Ambiente \& Água - An Interdisciplinary Journal of Applied Science
ISSN 1980-993X - doi:10.4136/1980-993X
www.ambi-agua.net
E-mail: ambi-agua@agro.unitau.br

\title{
Avaliação do comportamento dinâmico da carga dissolvida e particulada fluvial de uma microbacia reflorestada com eucaliptos
}

\author{
doi: 10.4136/ambi-agua.1384
}

Received: 25 Apr. 2014; Accepted: 14 Jul. 2014

\author{
Diego Vendramini*; Helder de Oliveira; Jefferson Mortatti \\ Universidade de São Paulo (CENA/USP), Piracicaba, SP, Brasil \\ Laboratório de Isótopos Estáveis \\ *Autor correspondente: e-mail: diegovendra.eng@gmail.com, \\ helder@cena.usp.br, jmortatt@cena.usp.br
}

\section{RESUMO}

Os principais aspectos do comportamento dinâmico fluvial das cargas dissolvida e particulada de uma microbacia de drenagem reflorestada com eucaliptos em Angatuba (SP) foram avaliados durante dois eventos chuvosos de 28 e $25 \mathrm{~mm}$, respectivamente antes e após o corte da madeira. Para a carga dissolvida foi possível observar que as concentrações dos cátions e ânions variaram inversamente com a vazão, evidenciando mecanismos de diluição, mas com significante contribuição no processo de subida das águas, antes dos picos das vazões, em função da contribuição proveniente do escoamento superficial. A comparação entre as curvas de distribuição das mesmas com os respectivos modelos de diluição teórica evidenciou predomínio de aportes difusos, mas com significativa contribuição dos tratos culturais e adubação exercidas na microbacia (casos de $\mathrm{K}^{+}, \mathrm{Cl}^{-}$e $\mathrm{SO}_{4}{ }^{2-}$ ), principalmente na amostragem realizada posterior ao corte de madeira. Em termos de carga particulada, as concentrações de material particulado em suspensão (MPS) se relacionaram positivamente com a vazão nos dois períodos estudados, indicando maior transporte deste material nas maiores vazões. $\mathrm{O}$ estudo da relação concentração-vazão permitiu evidenciar diferenças nas dinâmicas dos processos de remobilização e sedimentação, influenciadas pelos volumes das chuvas, condições de saturação dos solos na microbacia e regimes hidrológicos. Os fluxos específicos de MPS foram da ordem 2.330 e $2.121 \mathrm{~g} \mathrm{~km}^{-2} \mathrm{~h}^{-1}$, respectivamente antes e após o corte da madeira, indicando grande contribuição da área cultivada com eucaliptos para os processos erosivos mecânicos.

Palavras-chave: hidrogeoquímica, cargas fluviais, microbacias de drenagem.

\section{Dynamic behavior evaluation of the fluvial dissolved and particulate loads in a small catchment reforested with eucalyptus}

\begin{abstract}
The main aspects of dissolved and particulate loads dynamic behavior in a small catchment of reforested eucalyptus were evaluated for two rainfall events of 28 and $25 \mathrm{~mm}$ before and after clear cutting. For the dissolved load, cations and anions varied inversely with the discharge, showing mechanisms of dilution, but with significant inputs before high discharges. The comparison between distribution concentrations curves with their theoretical
\end{abstract}


dilution models revealed predominance of diffuse inputs, but with significant contribution of fertilization treatments, cases of $\mathrm{K}^{+}, \mathrm{Cl}^{-}$and $\mathrm{SO}_{4}{ }^{2-}$, mainly after clear cutting. The fluvial particulate load, represented by suspended particulate matter (SPM), showed a positive relationship with discharges, with greater concentrations in higher flow rates for both periods. The relationship between MPS concentrations and discharges showed differences in the dynamics of remobilization and sedimentation processes influenced by precipitation, saturated soils conditions and hydrological regimes. Specific flows of MPS were approximately 2330.1 and $2121.1 \mathrm{~g} \mathrm{~km}^{-2} \mathrm{~h}^{-1}$, before and after clear cutting, respectively, indicating a major effect of the eucalyptus planted area on mechanical erosion.

Keywords: hydrogeochemistry, fluvial loads, small catchments.

\section{INTRODUÇÃO}

As florestas homogêneas para exploração de madeira na indústria de papel e celulose vêm aumentando substancialmente no país nas últimas décadas, sendo o Brasil hoje o maior produtor mundial de celulose de eucalipto, com área plantada de mais 3 milhões de hectares (Carvalho et al., 2012). Aliado a esse crescimento, surge também a preocupação com possíveis impactos aos sistemas fluviais, principalmente em termos de suas cargas dissolvida e particulada, devido às intensivas práticas silviculturais associadas a esses processos.

Apesar desse tipo de cobertura vegetal ser importante para hidrologia do solo, promovendo equilíbrio no processo de infiltração, lixiviação, armazenamento da água e atenuação do escoamento superficial (Lima, 1986; Oliveira et al., 2009), algumas atividades como, por exemplo, o corte raso da floresta implantada podem, se mal planejadas e manejadas, provocar uma série de alterações nesses ambientes, tais como: perdas de nutrientes, erosão e assoreamento, decomposição de húmus e alterações biológicas, interferindo diretamente na qualidade das águas superficiais em microbacias de drenagem (Bormann et al., 1968; Câmara e Lima, 1999; Vital et al., 1999; Câmara et al., 2000).

De acordo com Betson e Marius (1969), Sidle et al. (1995) e Ahearn et al. (2004), de Moraes et al. (2006), a avaliação dessas possíveis alterações nos sistemas fluviais como, por exemplo, os que estão sob ocupação agrícola, pode ser realizada com a utilização de diferentes metodologias associadas ao controle físico-químico das águas e ao transporte de material em suspensão. Esse processo chama-se monitoramento hidrogeoquímico, que considera ainda efeitos globais e locais dessas alterações, tanto a níveis quantitativos quanto qualitativos (Mortatti, 1995).

Sobre essa temática, importantes estudos contemplando a avaliação do comportamento das cargas dissolvidas e particuladas, principalmente em grandes e médias bacias e mais recentemente em microbacias de drenagem têm sido realizados, buscando um melhor entendimento da dinâmica desses materiais transportados fluvialmente, observando suas variações naturais, mas também influências antrópicas. Esse é o caso, por exemplo, do estudo em bacia de drenagem com características agrícolas, datado da década de oitenta e realizado no rio Garone (França) com $9980 \mathrm{~km}^{2}$, onde para caracterização hidrogeoquímica do mesmo, Probst e Bazerbachi (1986) avaliaram as variabilidades das concentrações de algumas espécies químicas e das vazões, ao longo do período de 1981 a 1982. Os autores observaram que as concentrações de $\mathrm{SiO}_{2}, \mathrm{~K}^{+}$e $\mathrm{NO}_{3}{ }^{-}$aumentaram em função do aumento das vazões, assim como observado também para os sedimentos finos em suspensão. Tais aumentos nas concentrações foram associados às práticas agrícolas da região da bacia de drenagem.

Mais recentemente, Mortatti et al. (2003) avaliaram o comportamento dos principais cátions e ânions na bacia do rio Piracicaba $\left(12400 \mathrm{~km}^{2}\right)$, através das relações concentraçãovazão, comparando os resultados obtidos com as respectivas curvas de diluição teórica, tendo como objetivo evidenciar as possíveis origens dos aportes dessas espécies químicas 
inorgânicas dissolvidas estudadas nas águas fluviais desse importante curso d'água paulista. De acordo com os autores, a maioria das espécies estudadas apresentou comportamento de diluição das concentrações em função do aumento das vazões. Os aportes verificados de $\mathrm{Ca}^{2+}$, $\mathrm{Mg}^{2+}, \mathrm{HCO}_{3}{ }^{-}, \mathrm{Cl}^{-}, \mathrm{SO}_{4}{ }^{2-}$ e $\mathrm{SiO}_{2}$ se mostraram essencialmente de origem difusa, associados ao intemperismo de rochas e aportes atmosféricos, enquanto que os aportes evidenciados para $\mathrm{Na}^{+}, \mathrm{NH}_{4}{ }^{+} \mathrm{e} \mathrm{PO}_{4}{ }^{3-}$ estiveram relacionados à origem pontual, principalmente associados ao lançamento de esgotos brutos sem tratamento prévio. Apenas o $\mathrm{K}^{+}$apresentou aumento das concentrações em função das vazões se mostrando de origem difusa, mas associado a adubações realizadas ao longo da bacia de drenagem.

Ainda, para caracterização dos processos erosivos mecânicos e químicos predominantes da bacia do rio Sorocaba $\left(5269 \mathrm{~km}^{2}\right.$ ), Fernandes (2012) calculou os transportes específicos fluviais das principais espécies químicas inorgânicas dissolvidas e dos sedimentos finos em suspensão, baseado em dezoito meses de amostragem. Os resultados evidenciaram transportes mais significativos para $\mathrm{HCO}_{3}{ }^{-} \operatorname{com} 54,0 \mathrm{~kg} \mathrm{~km}^{-2} \mathrm{a}^{-1}$, seguido por $\mathrm{SiO}_{2} \operatorname{com} 25,3 \mathrm{~kg} \mathrm{~km}^{-2} \mathrm{a}^{-1} \mathrm{e}$ $\mathrm{Na}^{+}$com $24,3 \mathrm{~kg} \mathrm{~km}^{-2} \mathrm{a}^{-1}$. O transporte específico dos sedimentos finos em suspensão observado na foz da bacia de drenagem (Laranja Paulista - SP) foi de 55.695,8 $\mathrm{kg} \mathrm{km}^{-2} \mathrm{a}^{-1}$.

Estudos hidrogeoquímicos em microbacias de drenagem visando à observação dos aspectos relacionados ao comportamento das cargas dissolvidas e particuladas e principalmente sob influência de precipitações não são muito frequentes no Brasil.

Bibian (2007) avaliou na microbacia do córrego Barra Bonita $\left(29,31 \mathrm{~km}^{2}\right)$, localizada no estado de São Paulo, com intensa ocupação agrícola e urbana, o comportamento dinâmico desses materiais ao longo de dez excursões mensais e em uma amostragem intensiva, sob influência de precipitação de $60 \mathrm{~mm}$. De acordo com o autor, diferentemente dos padrões de diluição das concentrações das espécies químicas dissolvidas em função das vazões, observadas ao longo dos meses estudados, as concentrações dessas espécies na amostragem intensiva se mostraram positivas com aumento das vazões. Os transportes das cargas dissolvida e particulada na amostragem intensiva também apresentaram acréscimos em relação ao período de amostragens normal (mensal), sendo em torno de duas vezes para $\mathrm{K}^{+} \mathrm{e}$ $\mathrm{NH}_{4}{ }^{+}$e quatro vezes para $\mathrm{PO}_{4}{ }^{3-}$. Já para o material particulado em suspensão, esse acréscimo foi da ordem de quinzes vezes. Segundo o mesmo autor, tais aumentos podem estar associados à intensa atividade agrícola na referida microbacia como adubações com NPK, fertirrigação com vinhaça e processos erosivos mecânicos.

Além disso, boa parte dos estudos hidrogeoquímicos citados acima utilizaram métodos empíricos para avaliação das cargas dissolvidas e particuladas, os quais envolveram o estabelecimento de médias de concentrações e vazões durante um determinado período de tempo. A representatividade dessas médias, no entanto, se não realizadas em todas as fases da hidrógrafa, como por exemplo, nos períodos de águas baixas, de subidas das águas, nos picos de cheia e nos períodos de recesso, pode gerar valores superestimados ou subestimados, o que de acordo com Kattan (1989), Probst (1992) e Vendramini (2013) pode ser minimizado pela aplicação do método de fluxo instantâneo, o qual permite cálculos das relações entre concentrações e vazões em todos os períodos da hidrógrafa.

Todos esses fatos apresentados evidenciam a importância de estudos de eventos chuvosos isolados em microbacias de drenagem com características agrícolas permitindo, de forma mais detalhada, observar as variações dos comportamentos das espécies químicas dissolvidas e do material particulado em suspensão em todas as fases da hidrógrafa. Essas variações podem, por exemplo, estar associadas às mudanças no uso do solo, como no caso do corte raso da floresta de madeira, e aos processos hidrológicos envolvidos, mediante essas alterações, como nos casos das contribuições dos escoamentos superficiais, subsuperficiais e subterrâneos (Dunne, 1978; 1983; Bonell, 1988). Bonell (1991), atenta ao fato de que algumas modificações no uso da terra propiciam consideráveis variações nos processos 
hidrológicos e a avaliação desses processos depende do conhecimento de alguns fatores como, por exemplo, quantidade, intensidade e duração dos eventos chuvosos, mas também de aspectos geográficos/geológicos e tipos de uso e ocupação dos solos (Ahearn et al., 2004).

Neste contexto, o presente trabalho teve por objetivo avaliar a dinâmica da carga dissolvida e particulada em uma microbacia reflorestada com eucaliptos, sob influência de dois eventos chuvosos respectivos de 28 e $25 \mathrm{~mm}$, antes e depois do corte da madeira, por intermédio da aplicação de alguns modelos hidrogeoquímicos como o estudo variabilidade temporal, relações entre concentrações e vazões e estimativa dos fluxos instantâneos em todas as fases dos hidrogramas unitários gerados.

\section{MATERIAL E MÉTODOS}

\section{1. Área de estudo}

A microbacia Entre Rios está localizada no município de Angatuba (SP), entre os paralelos $23^{\circ} 16^{\prime} 30^{\prime \prime}$ e $23^{\circ} 17^{\prime} 30^{\prime \prime} \mathrm{S}$ e os meridianos $48^{\circ} 25^{\prime} 30^{\prime}$ ' e $48^{\circ} 26^{\prime} 30^{\prime \prime} \mathrm{O}$, a uma altitude média de $624 \mathrm{~m}$ e possui uma área de drenagem de $1,6 \mathrm{~km}^{2}$. Essa microbacia é composta por seis unidades de produção (talhões) com declividades entre $12 \%$ e $38 \%$, plantadas com diferentes espécies de eucaliptos em idades variando de três a nove anos. $\mathrm{O}$ corte da madeira com idade de 9 anos ocorreu em 10,2\% da área da microbacia Entre Rios em julho de 2007, como mostrado na Figura 1. Durante os períodos estudados, a área da microbacia esteve sobre intenso manejo agrícola decorrente de tratos culturais para obtenção de matéria-prima para produção de papel e celulose (Oliveira et al., 2009). Após supressão da floresta, os principais manejos na área da microbacia estiveram relacionados à correção do solo, com aplicação de gesso $\left(\mathrm{CaSO}_{4}\right)$, bem como adubação de pré-plantio, de plantio e adubação de cobertura, com respectivas aplicações de cinzas (restos vegetais) e NPK, sendo estas últimas três etapas realizadas entre os dias 20 de novembro e 01 de dezembro de 2007 (Vendramini, 2009).

O clima da região é do tipo Cfa, chuvoso com inverno frio, correspondendo ao mesotérmico úmido, de acordo com a classificação de Köppen (1948). Para o período de 1995 a 2007 a área da microbacia apresentou temperaturas mínima e máxima anual de $14,7{ }^{\circ} \mathrm{C}$ e $28,8{ }^{\circ} \mathrm{C}$ e precipitação média anual de $1499 \mathrm{~mm}$, com maiores volumes de chuva ocorrendo de dezembro a março (período chuvoso), com máximo de $281 \mathrm{~mm}$, e menores volumes de abril a setembro (período seco), com mínimo de $42 \mathrm{~mm}$ (Vendramini, 2009).

O domínio geológico local está principalmente associado ao Grupo São Bento, formação Pirambóia, composta basicamente por depósitos fluviais incluindo arenitos finos e médios avermelhados, síltico-argilosos, com estratificação cruzada ou plano paralela, com níveis de folhelhos e arenitos argilosos de cores variegadas e raras intercalações de natureza arenoargilosa (IPT, 1981).

Os principais grupos de solos encontrados na área da microbacia de drenagem, segundo critérios preconizados no Sistema Brasileiro de Classificação de Solos em Embrapa (2006) são: Latossolo Vermelho-Amarelo distrófico, fase arenosa (LVAd), Latossolo Vermelho, distrófico, fase argilosa (LVd), sendo que estes se encontram localizados na porção noroeste da microbacia, próximos as nascentes dos afluentes do córrego Entre Rios, bem como por Cambissolo Háplico Tb distrófico (CXbd), com horizonte $\mathrm{B}$ incipiente e Neossolo Quartzarênico ótico (RQo), constituídos essencialmente por material quartzoso não apresentando horizonte $\mathrm{B}$, os quais se encontram respectivamente nas porções nordeste e sudoeste da microbacia de drenagem, próximas ao ponto de coleta. 


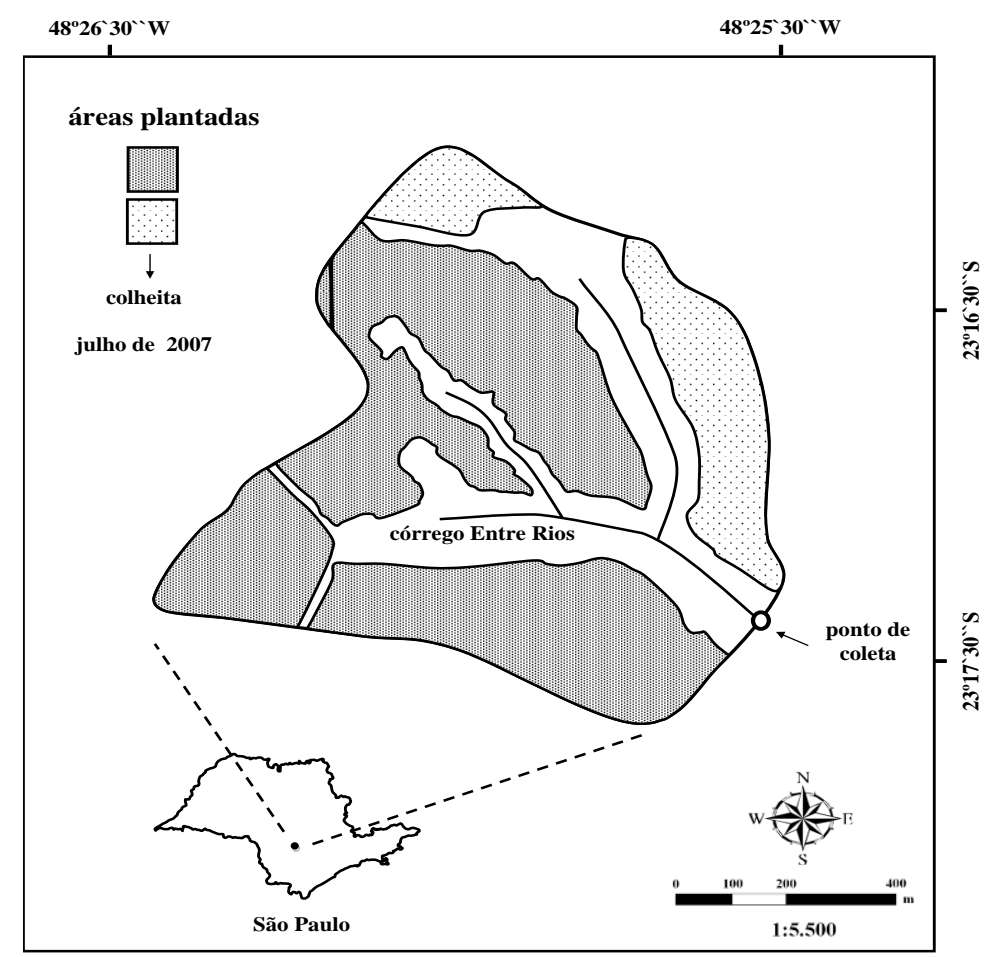

Figura 1. Localização do ponto de coleta na foz da microbacia de drenagem do córrego Entre Rios, no município de Angatuba, São Paulo e as respectivas áreas de plantio e de colheita da madeira.

\subsection{Protocolo de Amostragem}

As coletas das águas fluviais do córrego Entre Rios para a avaliação dos principais aspectos dinâmicos da carga dissolvida (cátions e ânions majoritários) e particulada (material particulado em suspensão - MPS), designadas de amostras brutas, foram efetuadas no eixo principal da corrente fluvial em duas situações distintas, a primeira entre os dias 17 e 18 de março de 2007, anterior ao corte da madeira e correspondendo a um evento chuvoso de 28 mm durante aproximadamente $16 \mathrm{~h}$ e a segunda, posterior ao corte da madeira em 05 de dezembro de 2007, sob um evento chuvoso de $25 \mathrm{~mm}$ e durante aproximadamente $13 \mathrm{~h}$, sendo coletadas nas duas situações um total de 9 amostras representativas de todas as fases da hidrógrafa. Os volumes coletados tanto para a avaliação da carga dissolvida quanto particulada foram de $1000 \mathrm{~mL}$, sendo os mesmos acondicionados em frascos de polietileno e mantidos a $4^{\circ} \mathrm{C}$ até a realização das análises.

As vazões instantâneas foram determinadas utilizando-se um vertedouro triangular de $90^{\circ}$, instalado no canal fluvial junto à foz da microbacia do córrego Entre Rios. Para a determinação das vazões instantâneas, durante os períodos estudados, adotou-se a fórmula de Thompson (Bos, 1976), conforme evidenciado na Equação 1. A altura da lâmina d'água foi medida por régua limnimétrica instalada de acordo com sugerido por Cruciani (1993) quando da utilização de vertedouros triangulares de $90^{\circ}$ e as vazões obtidas pelo estabelecimento de curvas-chave entre cotas e vazões.

$$
\mathrm{Q}=0,014 \mathrm{H}^{2,5}
$$

em que:

Q, é a vazão em $\mathrm{L} \mathrm{s}^{-1}$,

$\mathrm{H}$, é a altura da lâmina d'água em cm e

0,014, é o coeficiente de carga hidráulico. 
Os dados referentes às precipitações e os volumes amostrados durante os dois eventos chuvosos foram obtidos junto à estação meteorológica da Fazenda Entre Rios, distante cerca de 1.400 metros em relação ao ponto de amostragem das águas fluviais.

\subsection{Protocolo Analítico}

Os principais parâmetros físico-químicos $\mathrm{pH}$, condutividade elétrica $(\mathrm{CE})$, temperatura (T) e oxigênio dissolvido (OD) das águas fluviais da microbacia do córrego Entre Rios, nos dois períodos estudados, foram determinados em campo com a utilização de equipamentos portáteis de marca Digimed, modelos DM2 e DM4. Para determinação das concentrações das principais espécies químicas inorgânicas dissolvidas, cerca de $500 \mathrm{~mL}$ de amostras brutas foram filtradas a vácuo com utilização de bombas manuais em membranas de acetato de celulose de 0,45 $\mu \mathrm{m}$ ( $47 \mathrm{~mm}$ de diâmetro) e alíquotas de $100 \mathrm{~mL}$ foram analisadas em termos de cátions $\left(\mathrm{Ca}^{2+}, \mathrm{Mg}^{2+}, \mathrm{Na}^{+}, \mathrm{K}^{+}\right.$e $\left.\mathrm{NH}_{4}{ }^{+}\right)$e ânions $\left(\mathrm{Cl}^{-}, \mathrm{SO}_{4}{ }^{2-}, \mathrm{NO}_{3}{ }^{-}\right.$e $\left.\mathrm{PO}_{4}{ }^{3-}\right)$ dissolvidos, em triplicata, por cromatografia iônica. Outras alíquotas de $25 \mathrm{~mL}$ foram destinadas para análise da alcalinidade total, atribuída à atividade do íon bicarbonato $\left(\mathrm{HCO}_{3}{ }^{-}\right)$, também em triplicata por microtitulação de Gran, segundo metodologia descrita por Edmond (1970). Para a determinação da sílica dissolvida $\left(\mathrm{SiO}_{2}\right)$ alíquotas de $100 \mathrm{~mL}$ foram preservadas com ácidos sulfúrico concentrado na razão $0,1 \mathrm{~mL}$ por $100 \mathrm{~mL}$ de amostra e analisadas por espectrometria de emissão ótica com plasma acoplado indutivamente (ICP-OES).

A quantificação das concentrações do material particulado em suspensão (MPS) foi realizada por gravimetria, de acordo com o proposto Meade (1985). Para tal, foi necessária em primeira instância uma filtração prévia em peneira de nylon de $63 \mu \mathrm{m}$. Posteriormente cerca de $300 \mathrm{~mL}$ das amostras de águas fluviais foram filtradas em membranas de acetato de celulose de $0,45 \mu \mathrm{m}$ ( $47 \mathrm{~mm}$ de diâmetro) previamente pesadas, após secagem em estufa a 60 ${ }^{\circ} \mathrm{C}$ por 24 horas e em dessecador com sílica gel por mais 48 horas. Após a etapa de filtração, o conjunto composto por filtro e material particulado contidos nos filtros foi novamente destinado aos mesmos processos de secagem e pesagem para obtenção da massa final seca de MPS.

\subsection{Carga dissolvida}

A fim de se ter uma visão mais ampla do comportamento dinâmico da carga dissolvida do córrego Entre Rios, para os hidrogramas de cheia unitários gerados nos períodos antes e depois do corte da madeira, foram empregados modelos hidrogeoquímicos utilizados até então, de forma mais abrangente, somente em bacias de drenagem de grande e médio porte. Tais modelos envolveram a observação das variabilidades temporais e relações entre as concentrações das principais espécies químicas inorgânicas dissolvidas em relação às flutuações das vazões, bem como a quantificação da carga fluvial dissolvida por meio da somatória dos fluxos instantâneos gerados em cada fase dos respectivos hidrogramas de cheia unitários.

As concentrações médias das principais espécies químicas fluviais foram normalizadas pelas respectivas vazões instantâneas, conforme procedimento sugerido por Kattan (1989), por meio da Equação 2:

$$
C_{M N Q(E S P)}=\frac{\sum_{i=1}^{n=9}\left(Q_{i} \cdot C_{i}\right)}{\sum_{i=1}^{n=9} Q_{i}}
$$

em que:

$\mathrm{C}_{\mathrm{MNQ}(\mathrm{ESP})}$ é a concentração média das principais espécies químicas inorgânicas dissolvidas normalizadas pelas vazões instantâneas em cada período de amostragem $\left(\mathrm{mg} \mathrm{L}^{-1}\right)$,

$\mathrm{Q}_{\mathrm{i}}$, é a vazão instantânea medida em cada amostragem $\left(\mathrm{L} \mathrm{s}^{-1}\right)$, 
$\mathrm{C}_{\mathrm{i}}$ as concentrações das principais espécies químicas medidas em cada amostragem $\left(\mathrm{mg} \mathrm{L}^{-1}\right) \mathrm{e}$

$\sum \mathrm{Q}_{\mathrm{i}}$ é a somatória das vazões nos respectivos períodos estudados de amostragem $\left(\mathrm{L} \mathrm{s}^{-1}\right)$.

\subsection{Relação concentração-vazão: aportes difusos e pontuais}

O estudo da dinâmica da carga dissolvida do córrego Entre Rios foi complementado pela aplicação do modelo de regressão bi-logarítimica ou de potência entre as concentrações das espécies químicas inorgânicas dissolvidas e as respectivas vazões instantâneas. De acordo com Hall (1971) e Prosbt (1992) o estudo e modelagem dessas relações permitem caracterizar os mecanismos susceptíveis de influenciar ou de controlar o comportamento das espécies dissolvidas fluviais e identificar possíveis origens das mesmas em bacias de drenagem. De acordo ainda com Kattan e Probst (1987), Mortatti et al. (2008) e Vendramini et al. (2013), tais curvas modelam a situação de diluição de uma espécie química em cada estágio da hidrógrafa, onde as concentrações mais baixas estão associadas às maiores vazões e viceversa.

A identificação dos aportes difusos e pontuais foi realizada em função da comparação com as curvas de diluição teórica (equação 3), calculadas para cada espécie estudada, de acordo com procedimento descrito por Kattan e Probst, (1987) para a bacia do Moselle (França), e utilizado por Probst et al. (1992) para as bacias dos rios Congo e Ubangi (África), por Mortatti et al. (2003) para as bacias dos rios Tietê e Piracicaba (SP) e por Bibian (2007) para microbacia do córrego Barra Bonita (SP). O deslocamento ou não do ajuste de potência, relativo à distribuição das concentrações observadas, em comparação com as curvas de diluição teórica, pode mostrar se os aportes dessas espécies químicas na bacia de drenagem ocorrem de maneira pontual (característicos de despejos de efluentes domésticos) ou difusa (intemperismo de rochas, aportes pluviais e resíduos agrícolas), evidenciando-se assim os principais mecanismos de controle de entrada dessas espécies químicas nas águas fluviais. Os aportes difusos configuram-se pela não proximidade entre as curvas relativas às distribuições das concentrações e as curvas de diluição teórica. Esse processo acontece porque o aporte das espécies químicas ocorre de forma bastante significativa e ao longo de toda área de drenagem, fazendo com que o processo de diluição das concentrações dessas espécies não seja tão expressivo, mesmo com aumentos substanciais do volume de água promovidos pelas precipitações e posteriormente por contribuições superficiais, subsuperficiais e subterrâneas. Já os aportes pontuais caracterizam-se pela proximidade entre as referidas curvas, o que significa dizer que os aportes das espécies químicas dissolvidas ocorrem em menores quantidades e em determinados pontos da área de drenagem representativa, sendo que suas diluições são diretamente proporcionais aos aumentos das vazões.

$$
C_{i}=\frac{C_{m a ́ x} \cdot Q_{m i ́ n}}{Q_{i}}
$$

em que:

$\mathrm{C}_{\mathrm{i}}$ é a concentração de uma determinada espécie química na curva de diluição teórica $\left(\mathrm{mg} \mathrm{L}{ }^{1}\right)$,

$\mathrm{C}_{\text {máx }}$ e $\mathrm{Q}_{\text {mín }}$ correspondem respectivamente a concentração máxima de determinada espécie química $\left(\mathrm{mg} \mathrm{L}^{-1}\right)$ e a vazão mínima instantânea, observadas em cada período estudado e $\mathrm{Q}_{\mathrm{i}}$ é a vazão instantânea de cada amostragem nos referidos períodos $\left(\mathrm{L} \mathrm{s}^{-1}\right)$. 


\subsection{Quantificação da Carga Dissolvida Fluvial}

A carga dissolvida fluvial na microbacia do córrego Entre Rios foi estimada pela somatória dos fluxos instantâneos obtidos entre as concentrações das espécies químicas estudadas e as respectivas vazões instantâneas geradas em todas as fases dos dois hidrogramas de cheia unitários (antes e depois do corte), conforme metodologia descrita por Kattan (1989) e expressada pela Equação 4.

$$
\mathrm{F}_{\mathrm{TAC}(\mathrm{ESP}) \mathrm{e}} \mathrm{F}_{\mathrm{TDC}(\mathrm{ESP})}=\sum_{\mathrm{i}=1}^{\mathrm{n}=9} \mathrm{C}_{\mathrm{i}} \cdot \mathrm{Q}_{\mathrm{i}} \cdot 3,6
$$

em que:

$\mathrm{F}_{\mathrm{TAC}(\mathrm{ESP})}$ e $\mathrm{F}_{\mathrm{TDC}(\mathrm{ESP})}$ são somatórias dos fluxos instantâneos totais de cada espécie química para cada hidrograma de cheia unitário $\left(\mathrm{g} \mathrm{h}^{-1}\right)$,

$\mathrm{n}=9$, é o número de amostragens realizadas respectivamente antes e após o corte da madeira,

$\mathrm{C}_{\mathrm{i}}$, é a concentração das espécies químicas dissolvidas para cada amostragem durante os períodos estudados,

$\mathrm{Q}_{\mathrm{i}}$, é a vazão instantânea correspondente a cada amostragem e o fator

3,6 corresponde à conversão das unidades de massa e tempo no cálculo do transporte fluvial em gramas por hora.

Os fluxos instantâneos específicos ( $\mathrm{F}_{\mathrm{EAC}(\mathrm{ESP})}$ e $\left.\mathrm{F}_{\mathrm{EDC}(\mathrm{ESP})}\right)$ das principais espécies químicas dissolvidas foram calculados pela razão entre os fluxos totais obtidos em cada período estudado e a área da microbacia de drenagem.

\subsection{Carga particulada}

Para avaliação da dinâmica do material particulado fluvial, composto principalmente por sedimentos finos em suspensão (MPS $<63 \mu \mathrm{m}$ ), as concentrações foram quantificadas por gravimetria e posteriormente normalizadas pelas respectivas vazões instantâneas. Os mesmos procedimentos metodológicos já descritos para a carga dissolvida, referentes ao estudo da relação concentração-vazão e da quantificação da carga particulada antes e depois do corte da madeira ( $\mathrm{F}_{\mathrm{TAC}(\mathrm{MPS})}$ e $\mathrm{F}_{\mathrm{EAC}(\mathrm{MPS})} ; \mathrm{F}_{\mathrm{TDC}(\mathrm{MPS})}$ e $\mathrm{F}_{\mathrm{EDC}(\mathrm{MPS})}$ ), em termos de fluxo total e específico, também foram utilizados para a avaliação do comportamento desse material nas águas fluviais do córrego Entre Rios.

\section{RESULTADOS E DISCUSSÃO}

As características dos dois hidrogramas unitários gerados em função das precipitações de 28 e $25 \mathrm{~mm}$, referente respectivamente às amostragens realizadas antes e depois do corte da madeira, podem ser verificadas na Figura 2, onde é possível observar as ocorrências dos picos de cheia em aproximadamente 2 horas, para ambos os casos.

As amostragens realizadas antes do corte da madeira tiveram início às 17:32 $\mathrm{h}$ do dia 17/03/2007 e término às 9:42 h no dia 18/03/2007, com uma duração total de 16,17 h. Já as amostragens realizadas após corte da madeira tiveram início às 9:30 h do dia 05/12/2007 e término às 22:55 h, correspondendo a um período total de 13,42 h. É importante salientar que as amostragens foram realizadas nos períodos chuvosos, no entanto, as condições de saturação dos solos da microbacia de drenagem no primeiro e segundo períodos de coleta se mostraram diferentes. Enquanto que no primeiro período os solos se encontraram mais saturados, em função da ocorrência de significativos eventos de chuva nos 15 dias anteriores à realização das coletas, com precipitação acumulada de $177 \mathrm{~mm}$, o segundo período de amostragem foi 
realizado após 10 dias sem chuvas intensas, o que provavelmente corroborou para os diferentes regimes de vazões e configurações dos hidrogramas unitários isolados (Figura 2), especialmente quando observado seus períodos de recesso, que apresentaram suas definições após 10 e 7 horas, respectivamente, mesmo com classes de precipitação semelhantes.
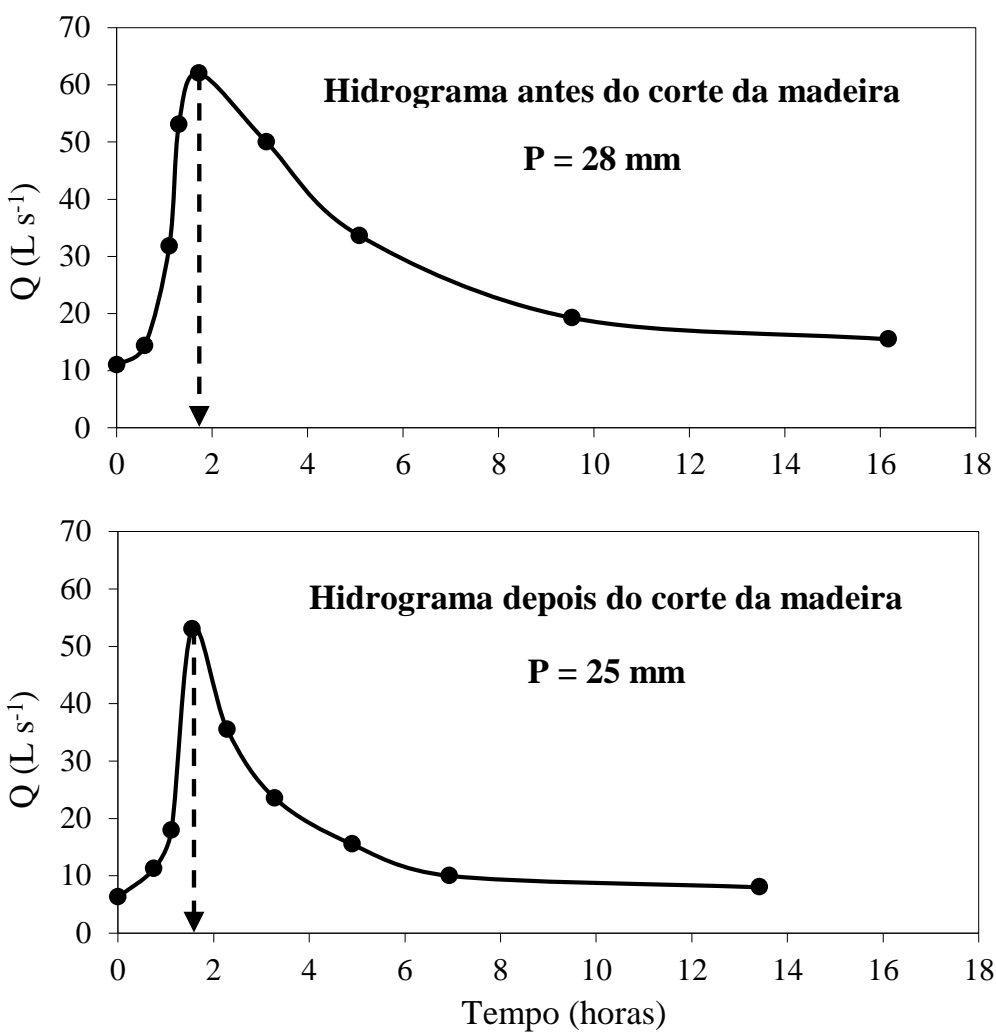

Figura 2. Hidrogramas de cheia unitários referente aos períodos de amostragens de águas fluviais antes e depois do corte da madeira, realizadas respectivamente entre os dias 17 e 18/03/2007 e 05/12/2007, na microbacia do córrego Entre Rios, Angatuba, São Paulo.

De acordo com Vendramini (2009), o tipo predominante de escoamento observado para os dois eventos chuvosos estudados na microbacia de drenagem, e verificado mediante a aplicação da metodologia de filtros numéricos auto-recursivos de $1^{\mathrm{a}}$ ordem (Hino e Hasebe, 1984), foi subterrâneo, com cerca de 66 e 69\%, respectivamente, para as amostragens antes e depois do corte, enquanto que o superficial foi de 34 e $31 \%$. É importante ressaltar, porém, que a metodologia utilizada para verificar tais escoamentos levou em consideração o método de dois reservatórios, superficial e subterrâneo, considerando este último como sendo a somatória das contribuições subsuperficial e subterrânea. Tais valores evidenciaram de forma mais detalhada a influência das condições de saturação dos solos na região estudada. No segundo período de amostragens (após o corte), com solos menos saturados, foi possível evidenciar maior a contribuição da componente subterrânea, o que possivelmente está associado ao rápido processo de infiltração das águas pluviais e consequentemente contribuição para o escoamento total.

\subsection{Variabilidade dos parâmetros físico-químicos}

Os resultados dos principais parâmetros físico-químicos $\mathrm{pH}$, condutividade elétrica (CE em $\mu \mathrm{S} \mathrm{cm}^{-1}$ ), temperatura $\left(\mathrm{T} \mathrm{em}{ }^{\circ} \mathrm{C}\right)$, oxigênio dissolvido (OD em $\mathrm{mg} \mathrm{L}^{-1}$ ) e das vazões 
instantâneas $\left(\mathrm{Q}\right.$ em $\left.\mathrm{L} \mathrm{s}^{-1}\right)$ obtidos para os dois períodos de amostragem podem ser observados na Tabela 1.

Tabela 1. Resultados dos principais parâmetros físico-químicos e vazões instantâneas determinadas para as águas fluviais do córrego Entre Rios.

\begin{tabular}{|c|c|c|c|c|c|c|c|}
\hline Amostras & $\begin{array}{c}\text { Excursão } \\
\text { (data) }\end{array}$ & $\begin{array}{l}\text { Tempo } \\
\text { (h) }\end{array}$ & $\begin{array}{c}\mathbf{Q} \\
\left(\mathbf{L ~ s}^{-1}\right)\end{array}$ & pH & $\begin{array}{c}\text { OD } \\
\left(\mathrm{mg} \mathrm{L}^{-1}\right)\end{array}$ & $\begin{array}{c}\text { Cond. } \\
\left(\mu \mathrm{S} \mathrm{cm}^{-1}\right)\end{array}$ & $\begin{array}{c}\mathrm{T} \\
\left({ }^{\circ} \mathrm{C}\right)\end{array}$ \\
\hline $\mathrm{A}_{1.1}$ & $17 / 03 / 07$ & $17: 32$ & 11,0 & 6,3 & 7,4 & 24,8 & 22,8 \\
\hline $\mathrm{A}_{1.2}$ & 17/03/07 & 18:07 & 14,3 & 6,4 & 6,9 & 26,4 & 22,7 \\
\hline $\mathrm{A}_{1.3}$ & 17/03/07 & $18: 38$ & 31,8 & 6,3 & 6,2 & 21,3 & 22,7 \\
\hline $\mathrm{A}_{1.4}$ & 17/03/07 & $18: 50$ & 53,0 & 6,2 & 6,4 & 20,5 & 22,6 \\
\hline $\mathrm{A}_{1.5}$ & 17/03/07 & 19:15 & 62,0 & 6,2 & 6,1 & 20,0 & 22,7 \\
\hline $\mathrm{A}_{1.6}$ & 17/03/07 & 20:40 & 50,0 & 6,1 & 6,3 & 20,0 & 22,6 \\
\hline $\mathrm{A}_{1.7}$ & $17 / 03 / 07$ & $22: 37$ & 33,6 & 6,1 & 5,6 & 19,1 & 22,6 \\
\hline $\mathrm{A}_{1.8}$ & 18/03/07 & 03:04 & 19,2 & 6,2 & 5,9 & 19,0 & 22,8 \\
\hline $\mathrm{A}_{1.9}$ & $18 / 03 / 07$ & 09:42 & 15,5 & 6,1 & 5,2 & 19,9 & 25,5 \\
\hline $\mathrm{A}_{2.1}$ & 05/12/07 & 09:30 & 6,3 & 6,4 & 3,7 & 26,3 & 25,3 \\
\hline $\mathrm{A}_{2.2}$ & 05/12/07 & $10: 15$ & 11,2 & 6,4 & 3,6 & 23,0 & 24,9 \\
\hline $\mathrm{A}_{2.3}$ & 05/12/07 & 10:37 & 17,9 & 6,3 & 3,4 & 26,1 & 25,1 \\
\hline $\mathrm{A}_{2.4}$ & 05/12/07 & 11:03 & 53,0 & 6,3 & 3,0 & 24,5 & 25,1 \\
\hline $\mathrm{A}_{2.5}$ & 05/12/07 & $11: 47$ & 35,5 & 6,2 & 3,5 & 24,0 & 24,7 \\
\hline $\mathrm{A}_{2.6}$ & 05/12/07 & $12: 47$ & 23,5 & 6,2 & 3,4 & 21,2 & 24,9 \\
\hline $\mathrm{A}_{2.7}$ & 05/12/07 & $14: 24$ & 15,5 & 6,2 & 3,3 & 22,3 & 25,0 \\
\hline $\mathrm{A}_{2.8}$ & 05/12/07 & $16: 26$ & 10,0 & 6,4 & 3,8 & 20,6 & 24,2 \\
\hline $\mathrm{A}_{2.9}$ & $05 / 12 / 07$ & $22: 55$ & 8,0 & 6,5 & 3,8 & 20,9 & 25,0 \\
\hline
\end{tabular}

$\mathrm{A}_{1.1}$ a $\mathrm{A}_{1.9}$ representam o período de amostragem antes do corte da madeira

$\mathrm{A}_{2.1}$ a $\mathrm{A}_{2.9}$ representam o período de amostragem depois do corte da madeira

Em ambos os períodos estudados em todas as fases da hidrógrafa, a distribuição do pH apresentou comportamentos similares, sempre abaixo da neutralidade, com valores variando entre 6,1 e 6,5. Valores de pH semelhantes foram observados por Ranzini e Lima (2002) para duas distintas microbacias plantadas com Eucalyptus saligna Smith, situadas no município de Santa Branca (SP) e por Vital et al. (1999) em mais duas microbacias no Vale do Paraíba (SP).

Essa similaridade entre os períodos estudados também foi observada para a temperatura da água, que apresentou pouca variabilidade, com máximos e mínimos de 25,5 e $22,6{ }^{\circ} \mathrm{C}$, e de 25,3 e $24,2{ }^{\circ} \mathrm{C}$, respectivamente, para o primeiro e segundo períodos, assim como para a condutividade elétrica, que apresentou valores máximos e mínimos de 26,4 e $19,0 \mu \mathrm{S} \mathrm{cm}^{-1}$, para o período antes do corte, e de 26,3 e $20,6 \mu \mathrm{S} \mathrm{cm}^{-1}$, depois do corte. Sobre esse parâmetro, ainda é importante salientar que, apesar do evidente processo de diluição, os picos das vazões em ambas as amostragens não corresponderam aos de menores condutividades, o que pode estar relacionado aos processos hidrológicos envolvidos, referente às significativas contribuições dos escoamentos superficiais e subterrâneos. Em ambos os casos, os maiores valores de condutividade elétrica podem ser observados no processo de subida das águas (Amostras $\mathrm{A}_{1.2}$ e $\mathrm{A}_{2.2}$ e $\mathrm{A}_{2.3}$ da Tabela 2), quando do início das contribuições atmosféricas, onde possivelmente ocorreu uma contribuição mais significativa do escoamento superficial. Logo após esse processo, evidenciou-se um padrão mais evidente de diluição dos valores de condutividade, promovido provavelmente já pela significativa contribuição dos fluxos subterrâneos. Padrões comportamentais semelhantes quanto a esse parâmetro foram observados por Ahearn et al. (2004) em estudo das variações temporais da química das águas fluviais na bacia do Rio Consumnes (EUA).

Já as concentrações de OD nas águas fluviais do córrego Entre Rios apresentaram significativas variabilidades entre as amostragens, com valores entre 5,2 e 7,4 mg L-1, na primeira amostragem e entre 3,0 e $3,8 \mathrm{mg} \mathrm{L}^{-1}$, na segunda amostragem. De acordo com 
Oliveira et al. (2009), essa diminuição do oxigênio dissolvido nas águas fluviais do córrego Entre Rios, observada especialmente no período após o corte da madeira, pode estar associada a uma maior atividade microbiana, em função do significativo arraste de material orgânico contido nos solos desnudos da área de colheita de madeira para dentro do canal fluvial via escoamentos superficiais.

\subsection{Carga Dissolvida}

Na Tabela 2 podem ser observados os resultados das concentrações totais das principais espécies químicas inorgânicas dissolvidas presentes nas águas fluviais do córrego Entre Rios e as médias normalizadas pelas vazões, relativos aos períodos estudados antes e depois do corte da madeira. É importante salientar que os resultados analíticos dessas espécies mostraram desvios sempre inferiores a $10 \%$.

Tabela 2. Concentrações médias dos cátions, ânions, sílica dissolvida e sólidos dissolvidos totais (SDT), normalizadas pelas vazões $\left(\mathrm{C}_{\mathrm{MNQ}}\right.$, em $\left.\mathrm{mg} \mathrm{L}^{-1}\right)$, referente as amostragens antes $\left(\mathrm{A}_{1.1}\right.$ a 1.9$) \mathrm{e}$ depois do corte da madeira $\left(\mathrm{A}_{2.1} \mathrm{a}_{2.9}\right)$ nas águas fluviais do córrego Entre Rios.

\begin{tabular}{|c|c|c|c|c|c|c|c|c|c|c|c|c|}
\hline Amostras & $\mathrm{Ca}^{2+}$ & $\mathrm{Mg}^{2+}$ & $\mathrm{Na}^{+}$ & $\mathbf{K}^{+}$ & $\mathrm{NH}_{4}^{+}$ & $\begin{array}{c}\mathrm{SiO}_{2} \\
\left(\mathrm{mg} \mathrm{L}^{-1}\right)\end{array}$ & $\mathrm{HCO}_{3}^{-}$ & $\mathrm{Cl}^{-}$ & $\mathrm{SO}_{4}{ }^{2-}$ & $\mathrm{NO}_{3}^{-}$ & $\mathrm{PO}_{4}{ }^{3-}$ & SDT \\
\hline $\mathbf{A}_{1.1}$ & 1,68 & 0,46 & 0,60 & 1,71 & 0,04 & 10,40 & 8,20 & 0,90 & 0,40 & 0,42 & 0,01 & 24,83 \\
\hline $\mathbf{A}_{1.2}$ & 1,78 & 0,45 & 0,44 & 1,75 & 0,05 & 10,06 & 8,30 & 0,90 & 0,32 & 0,36 & 0,15 & 24,57 \\
\hline $\mathbf{A}_{1.3}$ & 1,60 & 0,40 & 0,40 & 1,72 & 0,04 & 9,11 & 7,25 & 0,90 & 0,45 & 0,40 & 0,02 & 22,30 \\
\hline $\mathbf{A}_{1.4}$ & 1,20 & 0,30 & 0,30 & 1,50 & 0,03 & 8,97 & 6,20 & 0,51 & 0,22 & 0,35 & 0,06 & 19,64 \\
\hline $\mathbf{A}_{1.5}$ & 1,00 & 0,30 & 0,35 & 1,50 & 0,02 & 7,74 & 5,30 & 0,64 & 0,36 & 0,38 & n.d. & 17,59 \\
\hline $\mathbf{A}_{1.6}$ & 1,32 & 0,25 & 0,42 & 1,62 & 0,02 & 8,56 & 5,90 & 0,65 & 0,37 & 0,48 & 0,08 & 19,67 \\
\hline $\mathbf{A}_{1.7}$ & 1,30 & 0,44 & 0,43 & 1,59 & 0,01 & 8,70 & 6,81 & 0,56 & 0,40 & 0,58 & 0,10 & 20,92 \\
\hline $\mathbf{A}_{1.8}$ & 1,50 & 0,44 & 0,46 & 1,55 & 0,02 & 9,58 & 7,10 & 0,80 & 0,50 & 0,56 & n.d. & 22,51 \\
\hline $\mathbf{A}_{1.9}$ & 1,67 & 0,47 & 0,49 & 2,00 & 0,02 & 9,83 & 7,60 & 1,30 & 0,80 & 0,50 & n.d. & 24,67 \\
\hline $\mathrm{C}_{\mathrm{MNQ}}$ & 1,33 & 0,35 & 0,40 & 1,61 & 0,02 & 8,81 & 6,46 & 0,71 & 0,38 & 0,44 & - & 20,54 \\
\hline $\mathrm{C}_{\text {máx }}$ & 1,78 & 0,47 & 0,60 & 2,00 & 0,05 & 10,40 & 8,30 & 1,30 & 0,80 & 0,58 & - & 24,83 \\
\hline $\mathbf{C}_{\text {mín }}$ & 1,00 & 0,25 & 0,30 & 1,50 & 0,01 & 7,74 & 5,30 & 0,51 & 0,22 & 0,35 & - & 17,59 \\
\hline $\mathbf{A}_{2.1}$ & 1,80 & 0,42 & 0,65 & 1,52 & n.d. & 8,82 & 8,20 & 0,76 & 0,60 & 0,34 & n.d. & 23,11 \\
\hline $\mathbf{A}_{2.2}$ & 1,41 & 0,38 & 0,41 & 1,94 & n.d. & 7,97 & 6,72 & 1,51 & 0,43 & 0,34 & 0,09 & 21,20 \\
\hline $\mathbf{A}_{2.3}$ & 1,90 & 0,50 & 0,48 & 3,68 & n.d. & 9,83 & 7,80 & 2,17 & 1,02 & 1,49 & 0,11 & 28,97 \\
\hline $\mathbf{A}_{2.4}$ & 1,30 & 0,35 & 0,30 & 2,65 & n.d. & 6,96 & 4,97 & 1,70 & 0,91 & 0,62 & n.d. & 19,76 \\
\hline $\mathbf{A}_{2.5}$ & 1,34 & 0,38 & 0,35 & 2,77 & n.d. & 5,88 & 5,21 & 2,46 & 0,73 & 0,49 & n.d. & 19,60 \\
\hline $\mathbf{A}_{2.6}$ & 1,51 & 0,43 & 0,30 & 2,57 & n.d. & 7,17 & 5,50 & 1,96 & 0,83 & 0,56 & n.d. & 20,83 \\
\hline $\mathbf{A}_{2.7}$ & 1,86 & 0,43 & 0,60 & 2,83 & n.d. & 8,31 & 6,75 & 1,96 & 0,99 & 0,96 & 0,17 & 24,84 \\
\hline $\mathbf{A}_{2.8}$ & 1,73 & 0,49 & 0,48 & 1,34 & n.d. & 7,45 & 7,26 & 0,89 & 1,08 & 0,37 & n.d. & 21,10 \\
\hline $\mathbf{A}_{2.9}$ & 1,55 & 0,57 & 0,70 & 2,20 & n.d. & 8,27 & 7,80 & 1,20 & 1,10 & 0,44 & n.d. & 23,83 \\
\hline $\mathbf{C}_{\mathrm{MNQ}}$ & 1,50 & 0,41 & 0,40 & 2,60 & - & 7,39 & 5,99 & 1,84 & 0,86 & 0,66 & - & 21,67 \\
\hline $\mathrm{C}_{\text {máx }}$ & 1,90 & 0,57 & 0,70 & 3,68 & n.d. & 9,83 & 8,20 & 2,46 & 1,10 & 1,49 & 0,17 & 28,97 \\
\hline$C_{\text {mín }}$ & 1,30 & 0,35 & 0,30 & 1,34 & n.d. & 5,88 & 4,97 & 0,76 & 0,43 & 0,34 & 0,09 & 19,60 \\
\hline
\end{tabular}

$\mathbf{C}_{\mathrm{MNQ}}=$ concentração média da espécie química normalizada pela vazão

$\mathbf{C}_{\text {máx }}=$ concentração máxima de cada espécie química no período de amostragem

$\mathbf{C}_{\mathbf{m i ́ n}}=$ concentração mínima de cada espécie química no período de amostragem

$\mathbf{A}_{\mathbf{1 . 1}}$ a $\mathbf{A}_{\mathbf{1 . 2}}$ representam a amostragem intensiva antes do corte

$\mathbf{A}_{2.1}$ a $\mathbf{A}_{2.2}$ representam a amostragem intensiva depois do corte

" n.d. " não determinado (< limite de detecção $=0,01 \mathrm{mg} \mathrm{L}^{-1}$ )

A caracterização química inorgânica das águas fluviais do córrego Entre Rios apresentou uma concentração média de sólidos dissolvidos totais (SDT) da ordem de $20,51 \mathrm{mg} \mathrm{L}^{-1}$ e 21,64 mg L $\mathrm{m}^{-1}$, onde o $\mathrm{SiO}_{2}$ e o $\mathrm{HCO}_{3}^{-}$foram as espécies químicas mais representativas com 
42,95 e $34,15 \%$ e 31,50 e $27,68 \%$, respectivamente, nos períodos antes e depois do corte da madeira. Também foi possível observar aumento das concentrações médias normalizadas pelas vazões para a maioria das espécies químicas estudadas, em especial para $\mathrm{K}^{+}, \mathrm{Cl}^{-}, \mathrm{Ca}^{2+} \mathrm{e}$ $\mathrm{SO}_{4}{ }^{2-}$ na segunda amostragem, as quais representaram respectivamente $12,01,8,50,6,93 \mathrm{e}$ $3,97 \%$, em relação ao SDT.

A dinâmica das concentrações das espécies químicas inorgânicas dissolvidas estudadas ao longo dos períodos se mostrou fortemente influenciada pelas recargas pluviais e pelos tipos de escoamentos envolvidos, evidenciando uma relação direta dos mesmos nas distribuições temporais das concentrações e regimes fluviométricos, conforme pode ser observado nas Figuras 3 e 4.
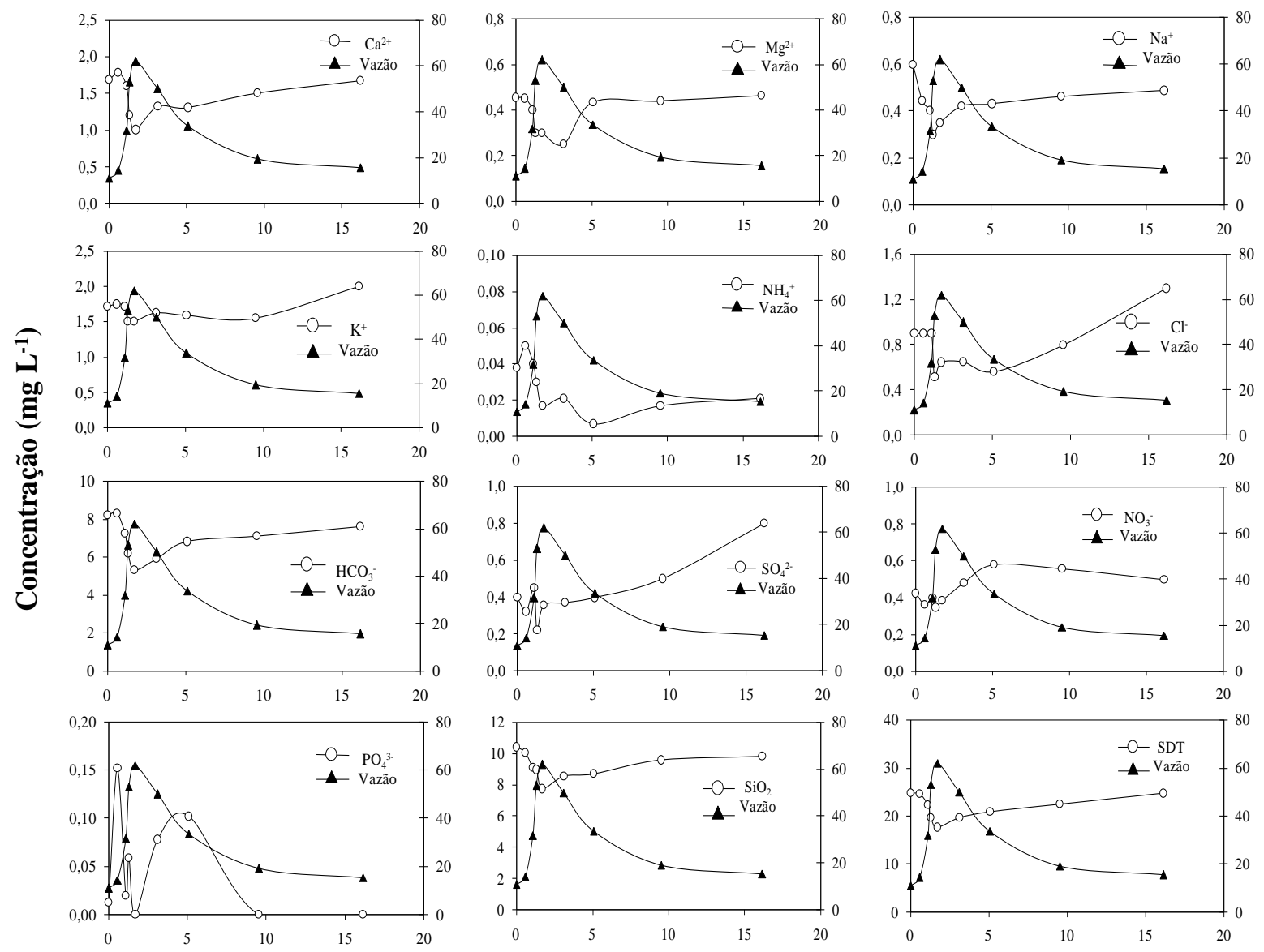

Tempo (horas)

Figura 3. Variabilidade temporal das concentrações de cátions, ânions, $\mathrm{SiO}_{2}$ e $\mathrm{SDT}\left(\mathrm{mg} \mathrm{L}^{-1}\right)$ em função das vazões $\left(\mathrm{L} \mathrm{s}^{-1}\right)$, na amostragem antes do corte da madeira (17 e 18/03/2007).

Foi possível observar, de forma geral, que algumas espécies químicas dissolvidas como, por exemplo, $\mathrm{NH}_{4}{ }^{+}, \mathrm{SO}_{4}{ }^{2-}$ e $\mathrm{PO}_{4}{ }^{3-}$ na primeira amostragem e $\mathrm{Ca}^{2+}, \mathrm{Mg}^{2+}, \mathrm{K}^{+}, \mathrm{NO}_{3}{ }^{-}$e $\mathrm{SiO}_{2}$ na segunda amostragem, apresentaram comportamentos bastante interessantes. Durante $\mathrm{O}$ processo de subidas das águas foi possível verificar elevados valores de suas concentrações, anteriormente aos picos de máximas vazões. Esses comportamentos das espécies químicas dissolvidas corroboram com evidenciado anteriormente para a dinâmica da condutividade elétrica, podendo em primeira instância estarem associadas à maior contribuição dos escoamentos superficiais, promovendo significativos aportes dessas espécies para o canal fluvial. Posteriormente a esse processo, já com a contribuição também do fluxo de base, as concentrações dessas espécies químicas dissolvidas atingem seus menores valores, concomitantemente com as mais elevadas vazões, caracterizando dessa forma um processo 
dinâmico de diluição desses sais presentes no corpo d'água. Esse fenômeno é considerado comum para maioria dos rios do mundo e pode estar associado a diversos fatores, como por exemplo, pelas recargas pluviais que promovem significativas variações do volume de água escoado nos sistemas fluviais (Probst et al., 1992), mas também aos processos hidrológicos decorrentes da mudança do uso do solo (Dunne e Black, 1970; Harriman et al., 1990; Beighley e Moglen, 2003; Ahearn et al., 2004).

A exceção se deu por parte das espécies químicas $\mathrm{K}^{+}$e $\mathrm{Cl}^{-}$, nas amostragens realizadas após o corte da madeira, que apresentaram aumento de suas concentrações mediante ao aumento das respectivas vazões instantâneas e imediatamente após a ocorrência do evento chuvoso.

Algumas $\mathrm{O} \mathrm{NH}_{4}{ }^{+}$e $\mathrm{PO}_{4}^{3-}$, em função de suas baixas concentrações, apresentaram comportamentos mais complexos, não sendo possível verificar padrões definidos para os mesmos.
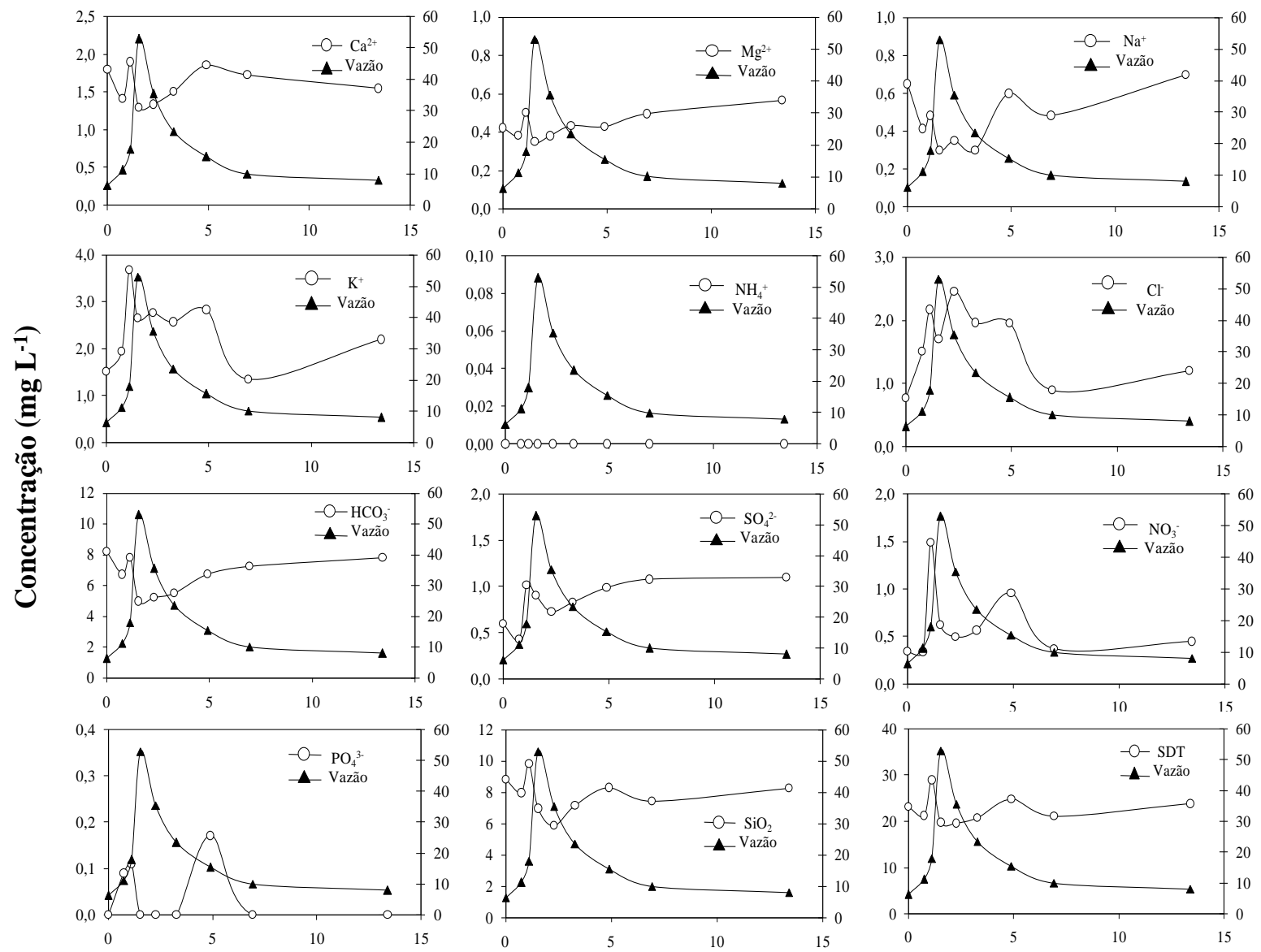

Tempo (horas)

Figura 4. Variabilidade temporal das concentrações de cátions, ânions, $\mathrm{SiO}_{2}$ e SDT (mg L $\left.{ }^{-1}\right)$ em função das vazões $\left(\mathrm{L} \mathrm{s}^{-1}\right)$, na amostragem depois do corte da madeira $(05 / 12 / 2007)$.

\subsection{Relação concentração-vazão: aportes difusos e pontuais}

As relações concentração-vazão e as respectivas curvas de diluição teórica calculadas para os principais cátions, ânions e sílica dissolvida podem ser observados nas Figuras 5 e 6 , procurando entender melhor a dinâmica dessas espécies químicas nas águas fluviais da microbacia de drenagem do córrego Entre Rios. Cabe salientar que as regressões de potência obtidas para todos os íons estudados e SDT foram significativas ao nível de $95 \%$ de probabilidade.

A utilização deste modelo permitiu de forma mais detalhada observar o comportamento 
de diluição das principais espécies químicas inorgânicas dissolvidas em relação à vazão, o que é considerado normal e característico e já foi evidenciado em médios e grandes rios (Moukolo et al., 1993; Mortatti, 1995; Mortatti et al., 2003 e Bortoletto Júnior, 2004).

As comparações entre as curvas de distribuições das concentrações dos íons estudados com as respectivas curvas de diluição teórica permitiram identificar as possíveis origens dessas espécies químicas nas águas do córrego Entre Rios, com base na proximidade ou distanciamento entre as mesmas.
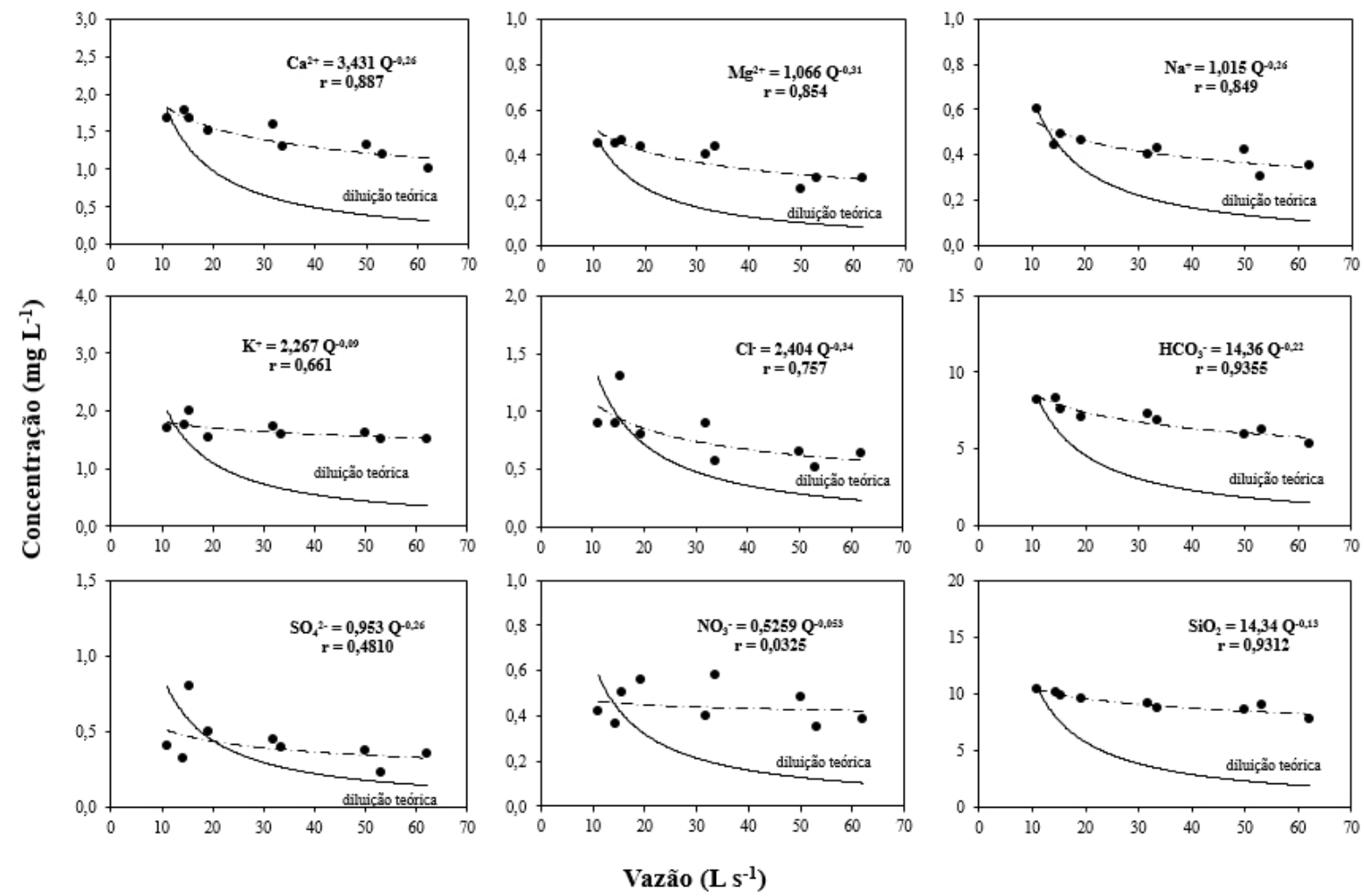

Figura 5. Relações concentração-vazão e as respectivas curvas de diluição teórica para os principais cátions, ânions e $\mathrm{SiO}_{2}$, obtidos para a microbacia do córrego Entre Rios, na amostragem realizada antes do corte da madeira (17e 18/03/2007).

Foi possível observar que os modelos de potência ajustados para explicar as distribuições das concentrações de $\mathrm{SiO}_{2}, \mathrm{Ca}^{2+}, \mathrm{Mg}^{2+}, \mathrm{Na}^{+}$e $\mathrm{HCO}_{3}{ }^{-}$nos dois períodos e também para $\mathrm{K}^{+}$e $\mathrm{NO}_{3}{ }^{-}$somente na primeira amostragem não seguiram as respectivas curvas de diluição teórica, apresentando um distanciamento entre elas. Este comportamento pode estar associado aos constantes aportes difusos dessas espécies ocorridas ao longo da microbacia de drenagem, fazendo com que as mesmas apresentem essa dinâmica independente das flutuações das vazões. Esses aportes podem estar relacionados aos processos de intemperismo de rochas presentes na microbacia, principalmente as silicatadas, como no caso dos íons $\mathrm{SiO}_{2}, \mathrm{HCO}_{3}{ }^{-}$, $\mathrm{Ca}^{2+}, \mathrm{Na}^{+}$e $\mathrm{Mg}^{2+}$, mas também aos aportes pluviais, como para $\mathrm{NO}_{3}{ }^{-}$e $\mathrm{K}^{+}$. De acordo com Vendramini (2009), em estudo na mesma microbacia de drenagem para o período entre outubro de 2006 e fevereiro de 2008, as contribuições dessas espécies químicas das águas das chuvas na carga dissolvida fluvial foram significativas, sendo praticamente de $100 \%$ para $\mathrm{NO}_{3}{ }^{-}$e $20 \%$ para $\mathrm{K}^{+}$, evidenciando expressiva contribuição da química das águas das chuvas na composição química das águas do córrego Entre Rios.

As concentrações de $\mathrm{Cl}^{-}$e $\mathrm{SO}_{4}{ }^{2-}$ nas amostragens realizadas antes do corte da madeira se mostraram próximas as suas respectivas curvas de diluição teórica, evidenciando possíveis aportes difusos (aportes atmosféricos), porém associadas à origem antrópica oriundos de 
tratos culturais ocorridos em determinadas áreas da microbacia de drenagem.

Por outro lado, as espécies químicas $\mathrm{K}^{+}, \mathrm{Cl}^{-}, \mathrm{NO}_{3}{ }^{-}$e $\mathrm{SO}_{4}{ }^{2-}$, especialmente nas amostragens realizadas depois do corte da madeira, apresentaram seus comportamentos inversos em relação às curvas de diluição teórica, aumentando suas concentrações em função do aumento das vazões, evidenciando também possível origem antrópica em seus aportes difusos. De acordo com Oliveira et al. (2009), tais aportes dessas espécies podem estar associados ao protocolo de adubações na área florestada realizado duas semanas antes das referidas amostragens, sendo possível observar seu efeito residual nas águas do córrego Entre Rios. Esse tipo de mobilidade principalmente para $\mathrm{K}^{+}, \mathrm{Cl}^{-}$e $\mathrm{NO}_{3}{ }^{-}$, após o primeiro ano do corte raso da madeira, já foi verificado em diversos trabalhos sobre ciclagem de nutrientes em microbacias reflorestadas (Feller e Kimmins, 1984; Hopmans et al., 1987; Stevens et al.; 1995; Ranzini e Lima, 2002; Guimarães et al., 2010). Segundo Hornbeck et al., (1975) e Vital et al. (1999), a perda de macronutrientes após o corte raso de florestas homogêneas é diretamente proporcional à área de colheita.
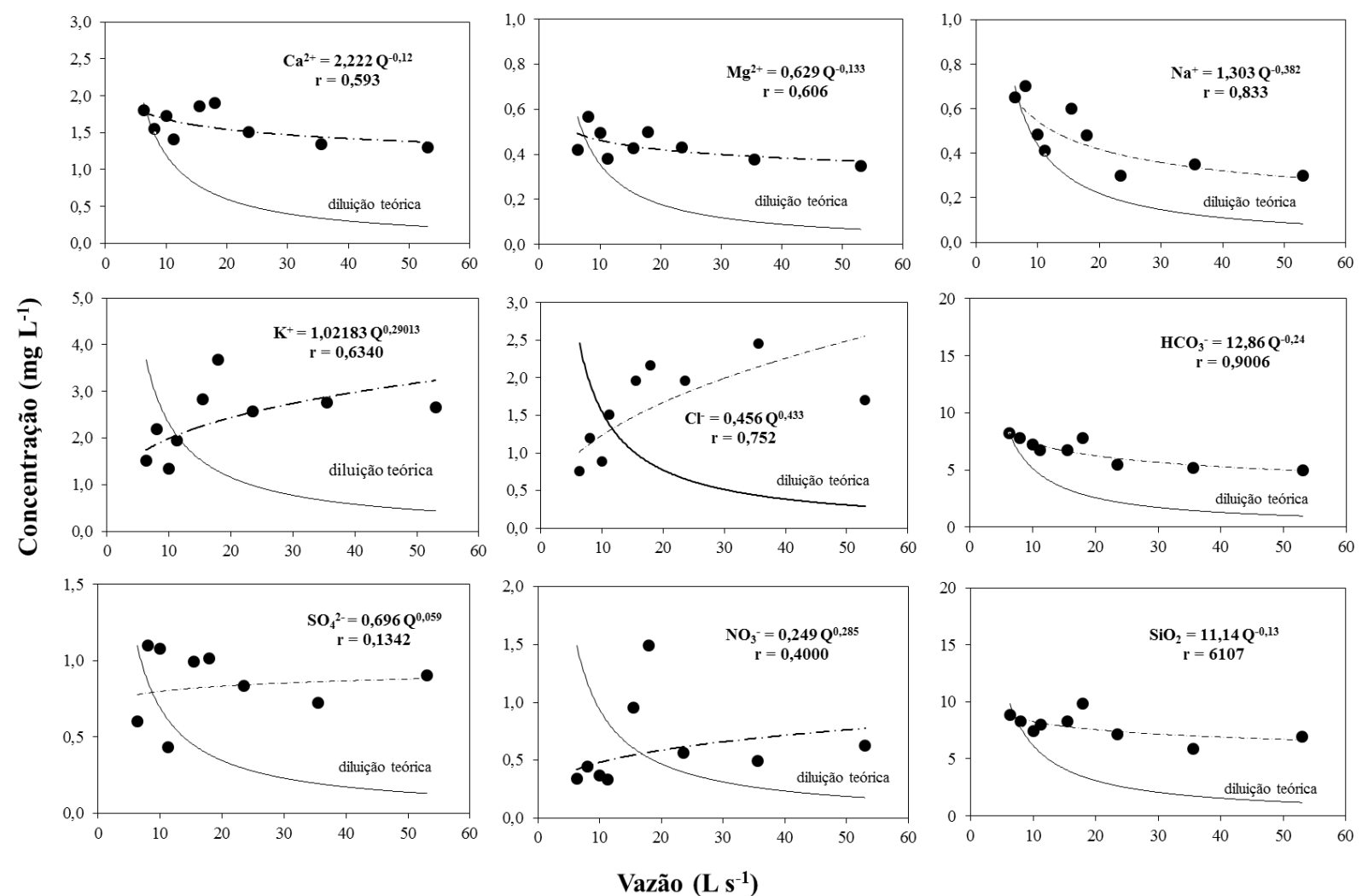

Figura 6. Relações concentração-vazão e as respectivas curvas de diluição teórica para os principais cátions, ânions e $\mathrm{SiO}_{2}$, obtidos para a microbacia do córrego Entre Rios, na amostragem realizada após o corte da madeira (05/12/2007).

\subsection{Quantificação da Carga Dissolvida Fluvial}

Os fluxos totais e específicos da carga inorgânica dissolvida do córrego Entre Rios, determinados pelo método de fluxo instantâneo ao longo dos períodos estudados, podem ser observados na Tabela 3.

Foi possível verificar que dentre as cargas dissolvidas totais transportadas fluvialmente, em ambos os períodos de amostragem, o $\mathrm{SiO}_{2}$ e o $\mathrm{HCO}_{3}{ }^{-}$foram as espécies químicas mais significativas, com fluxos totais respectivos de $9.217,6 \mathrm{e} 6.751,4 \mathrm{~g} \mathrm{~h}^{-1}$, antes do corte, e de $4.810,9$ e $3.902,0 \mathrm{~g} \mathrm{~h}^{-1}$, depois do corte, o que correspondeu a fluxos específicos de ordem de $5.761,0$ e $4.219,6 \mathrm{~g} \mathrm{~km}^{-2} \mathrm{~h}^{-1}$ e de $3.006,8$ e $2.438,7 \mathrm{~g} \mathrm{~km}^{-2} \mathrm{~h}^{-1}$. 
Apesar da baixa variabilidade verificada em termos de concentrações entre as duas amostragens realizadas antes e depois do corte da madeira (Tabela 2), foram observados aumentos significativos em termos de fluxos totais e específicos para $\mathrm{Cl}^{-}$e $\mathrm{SO}_{4}{ }^{2-}$, especialmente na segunda amostragem, sendo os mesmos da ordem de duas vezes. Essas constatações evidenciaram ainda mais suas importantes contribuições relacionadas à aplicação de insumos agrícolas em processos de adubação de plantio e de cobertura, conforme já comentado anteriormente e constatada pela análise da Figura 6.

Em termos comparativos com outras microbacias de drenagem, a carga dissolvida do córrego Entre Rios, representada em termos de fluxo específico de SDT de $8.823,6 \mathrm{~g} \mathrm{~km}^{-2} \mathrm{~h}^{-1}$, se mostrou superior a microbacia do córrego Barra Bonita $\left(29,30 \mathrm{~km}^{2}\right)$, localizada no Estado de São Paulo, com área de drenagem dezoito vezes superior a microbacia do córrego Entre Rios e sob significativa influência agrícola e antrópica, que apresentou 4.982,5 g km $\mathrm{g} \mathrm{h}^{-1}$ (Bibian, 2007) e também em relação às microbacias de Vachellerie $\left(5,65 \mathrm{~km}^{2}\right)$ e St. Bily $\left(3,91 \mathrm{~km}^{2}\right)$, localizadas na França, com cobertura de floresta de Pinus $s p$ e que na ocasião apresentaram fluxos específicos respectivos da ordem de 1.000 e $2375 \mathrm{~g} \mathrm{~km}^{-2} \mathrm{~h}^{-1}$ (Meybeck, 1986).

Tabela 3. Fluxos fluviais totais $\left(F_{\mathrm{TAC}(\mathrm{ESP})}\right.$ e $\left.\mathrm{F}_{\mathrm{TDC}(\mathrm{ESP})} \mathrm{em} \mathrm{g} \mathrm{h}^{-1}\right)$ e específicos $\left(\mathrm{F}_{\mathrm{EAC}(\mathrm{ESP})}\right.$ e $\mathrm{F}_{\mathrm{EDC}(\mathrm{ESP})} \mathrm{em} \mathrm{g}$ $\mathrm{km}^{-2} \mathrm{~h}^{-1}$ ) das principais espécies químicas inorgânicas dissolvidas calculadas pelo método de fluxo instantâneo, para os períodos de amostragens antes e depois do corte da madeira na microbacia do córrego Entre Rios.

\begin{tabular}{|c|c|c|c|c|c|}
\hline \multicolumn{3}{|c|}{$\begin{array}{l}\text { Amostragem antes do corte } \\
\text { Fluxo Instantâneo }\end{array}$} & \multicolumn{3}{|c|}{$\begin{array}{l}\text { Amostragem depois do corte } \\
\text { Fluxo Instantâneo }\end{array}$} \\
\hline Espécie & $\sum \mathbf{F}_{\mathrm{TAC}(\mathrm{ESP})}\left(\mathrm{g} \mathrm{h}^{-\mathbf{1}}\right)$ & $\sum \mathbf{F}_{\text {EAC(ESP) }}\left(\mathbf{g ~ k m}^{-2} \mathbf{h}^{-1}\right)$ & Espécie & $\sum \mathbf{F}_{\mathrm{TDC}(\mathrm{ESP})}\left(\mathrm{g} \mathrm{h}^{-\mathbf{1}}\right)$ & $\sum \mathbf{F}_{\text {EDC(ESP) }}\left(\mathrm{g} \mathrm{km}^{-2} \mathbf{h}^{-1}\right)$ \\
\hline $\mathrm{Ca}^{2+}$ & 1386,5 & 866,6 & $\mathrm{Ca}^{2+}$ & 977,4 & 610,8 \\
\hline $\mathrm{Mg}^{2+}$ & 365,4 & 228,4 & $\mathrm{Mg}^{2+}$ & 266,4 & 166,5 \\
\hline $\mathrm{Na}^{+}$ & 415,8 & 259,8 & $\mathrm{Na}^{+}$ & 260,8 & 163,0 \\
\hline $\mathrm{K}^{+}$ & 1678,7 & 1049,2 & $\mathrm{~K}^{+}$ & 1695,7 & 1059,8 \\
\hline $\mathrm{NH}_{4}^{+}$ & 25,2 & 15,7 & $\mathrm{NH}_{4}^{+}$ & n.d. & n.d. \\
\hline $\mathrm{SiO}_{2}$ & 9217,6 & 5761,0 & $\mathrm{SiO}_{2}$ & 4810,9 & 3006,8 \\
\hline $\mathrm{HCO}_{3}^{-}$ & 6751,4 & 4219,6 & $\mathrm{HCO}_{3}^{-}$ & 3902,0 & 2438,7 \\
\hline $\mathrm{Cl}^{-}$ & 738,7 & 461,7 & $\mathrm{Cl}^{-}$ & 1198,8 & 749,2 \\
\hline $\mathrm{SO}_{4}^{2-}$ & 399,6 & 249,8 & $\mathrm{SO}_{4}^{2-}$ & 558,7 & 349,2 \\
\hline $\mathrm{NO}_{3}^{-}$ & 456,2 & 285,1 & $\mathrm{NO}_{3}^{-}$ & 426,8 & 266,7 \\
\hline $\mathrm{PO}_{4}{ }^{3-}$ & 48,3 & 30,2 & $\mathrm{PO}_{4}{ }^{3-}$ & 20,3 & 12,7 \\
\hline SDT & 21483,3 & 13427,1 & SDT & 14117,7 & 8823,6 \\
\hline
\end{tabular}

"n.d." = não determinado (concentrações abaixo do limite de detecção)

É importante salientar que essas diferenças obtidas no presente estudo, em relação às bacias de drenagem citadas anteriormente podem estar associadas ao método empregado para estimativa dessas cargas dissolvidas. Nas microbacias citadas para comparação, tais cargas foram estimadas pelo emprego do método estocástico. Como este método depende de concentrações das espécies químicas e vazões médias, a representatividade desses parâmetros, caso não realizadas em todas as fases da hidrógrafa, como por exemplo, nos períodos de águas baixas, de subidas das águas, nos picos de cheia e nos períodos de recesso, pode gerar valores superestimados ou subestimados, como o que pode ter ocorrido nos referidos trabalhos. O que não foi o caso das estimativas realizadas no presente estudo empregando o método de fluxo instantâneo, onde foram representados fluxos (totais e específicos) ocorridos em todas as fases 
dos hidrogramas gerados durante os dois eventos chuvosos avaliados.

Tais evidências em relação à aplicação das metodologias se mostraram ainda mais significativas quando comparadas as estimativas dos fluxos específicos das principais espécies químicas, obtidos no presente estudo (método de fluxo instantâneo), com os transportes calculados tanto pelo método estocástico, quanto pelo método de integração de áreas, conforme realizado por Oliveira et al. (2009) para a mesma bacia de drenagem e sob influência dos mesmos eventos chuvosos, sendo que os resultados podem ser observados na Tabela 4.

Tabela 4. Tabela comparativa com os transportes específicos obtidos pelos métodos estocástico e de integração de áreas $\left(\mathrm{g} \mathrm{km}^{-2} \mathrm{~h}^{-1}\right)$ paras as principais espécies químicas dissolvidas nas águas fluviais do córrego Entre Rios, obtidos por Oliveira et al. (2009).

\begin{tabular}{|c|c|c|c|c|c|}
\hline \multicolumn{3}{|c|}{ Amostragem antes do corte } & \multicolumn{3}{|c|}{ Amostragem depois do corte } \\
\hline Espécie & $\begin{array}{c}\text { Estocástico } \\
T_{\text {ESTesp }}\left(\mathbf{g ~ k m}^{-2} \mathbf{h}^{-1}\right)^{*} \\
\end{array}$ & $\begin{array}{c}\text { Integração de Áreas } \\
T_{\text {IAesp }}\left(\mathrm{g} \mathrm{km}^{-2} \mathbf{h}^{-1}\right)^{*}\end{array}$ & Espécie & $\begin{array}{c}\text { Estocástico } \\
T_{\text {ESTesp }}\left(\mathrm{g} \mathrm{km}^{-2} \mathbf{h}^{-1}\right)^{*} \\
\end{array}$ & $\begin{array}{c}\text { Integração de Áreas } \\
T_{\text {IAesp }}\left(\mathrm{g} \mathrm{km}^{-2} \mathbf{h}^{-1}\right)^{*}\end{array}$ \\
\hline $\mathrm{Ca}^{2+}$ & 96,3 & 85 & $\mathrm{Ca}^{2+}$ & 67,9 & 53,8 \\
\hline $\mathrm{Mg}^{2+}$ & 25,4 & 23,8 & $\mathrm{Mg}^{2+}$ & 18,3 & 15 \\
\hline $\mathrm{Na}^{+}$ & 28,8 & 26,7 & $\mathrm{Na}^{+}$ & 17,9 & 15,4 \\
\hline $\mathrm{K}^{+}$ & 116,7 & 100,8 & $\mathrm{~K}^{+}$ & 117,9 & 80,8 \\
\hline $\mathrm{NH}_{4}^{+}$ & n.d. & n.d. & $\mathrm{NH}_{4}^{+}$ & n.d. & n.d. \\
\hline $\mathrm{SiO}_{2}$ & 640 & 554,6 & $\mathrm{SiO}_{2}$ & 334,2 & 255,4 \\
\hline $\mathrm{HCO}_{3}^{-}$ & 468,8 & 411,3 & $\mathrm{HCO}_{3}^{-}$ & 270,8 & 218,3 \\
\hline $\mathrm{Cl}^{-}$ & 51,3 & 46,3 & $\mathrm{Cl}^{-}$ & 83,3 & 57,1 \\
\hline $\mathrm{SO}_{4}{ }^{2-}$ & 27,9 & 27,9 & $\mathrm{SO}_{4}{ }^{2-}$ & 38,8 & 31,7 \\
\hline $\mathrm{NO}_{3}^{-}$ & 31,7 & 31,3 & $\mathrm{NO}_{3}^{-}$ & 29,6 & 20 \\
\hline $\mathrm{PO}_{4}^{3-}$ & n.d. & n.d. & $\mathrm{PO}_{4}{ }^{3-}$ & n.d. & n.d. \\
\hline SDT & 1486,7 & 1307,1 & SDT & 979,2 & 748,3 \\
\hline
\end{tabular}

* $\mathbf{T}_{\text {ESTesp }} \mathbf{e} \mathbf{T}_{\text {IAesp }}$ correspondem aos fluxos específicos calculados pelo método estocástico e de integração de áreas

(Oliveira et al., 2009)

"n.d." = não determinado

Por essa comparação foi possível evidenciar que os fluxos específicos obtidos pelo método de fluxo instantâneo (Tabela 3) se mostraram significativamente mais elevados do que os obtidos pelos dois métodos comparativos citados (Tabela 4), como por exemplo, para o $\mathrm{K}^{+}$(cátion mais abundante) que se mostrou maior 9 e 10 vezes, respectivamente, em relação aos métodos: estocástico e integração de áreas, na amostragem antes do corte e de 9 e 13 vezes após o corte da madeira. Já com relação ao $\mathrm{HCO}_{3}^{-}$(ânion mais abundante) essa discrepância se mostrou similar, sendo de 9 e 10 vezes antes do corte e de 9 e 11 vezes após o corte da madeira, em relação aos respectivos métodos. Uma provável justificativa para tais diferenças seria, conforme comentado anteriormente, pelo uso de médias das concentrações das espécies químicas normalizadas pelas vazões, sendo que o método estocástico utiliza tais médias para os períodos totais de ambos os hidrogramas de cheia e o método de integração para cada intervalo de tempo representativos das amostragens desses hidrogramas. Esse fato, aliado ao número de amostragens em períodos de baixas vazões podem ter resultado em menores valores de transportes específicos. 


\subsection{Carga Particulada}

Os resultados das concentrações do MPS, das vazões instantâneas e dos fluxos totais e específicos obtidos para os períodos de amostragem antes e depois do corte da madeira nas águas fluviais do córrego Entre Rios podem ser observados na Tabela 5.

Tabela 5. Concentrações de material particulado em suspensão (MPS em $\mathrm{mg} \mathrm{L}^{-1}$ ), médias normalizadas pelas vazões $\left(\mathrm{CMNQ}_{\mathrm{MPS}} \mathrm{em} \mathrm{mg} \mathrm{L}^{-1}\right)$ e vazões instantâneas $\left(\mathrm{L} \mathrm{s}^{-1}\right)$ para as amostras de águas fluviais do córrego Entre Rios, nos períodos antes de depois do corte da madeira, respectivamente entre 17 e 18/03 e 05/12/2007.

\begin{tabular}{ccc|ccc}
\hline \multicolumn{3}{c|}{ Amostragem antes do corte } & \multicolumn{3}{c}{ Amostragem depois do corte } \\
Amostras & $\begin{array}{c}\mathbf{Q} \\
\left(\mathbf{L ~ s} \mathbf{~ s}^{-\mathbf{1}}\right)\end{array}$ & $\begin{array}{c}\text { MPS } \\
\left(\mathbf{m g ~ L}^{\mathbf{- 1}}\right)\end{array}$ & Amostras & $\begin{array}{c}\text { Q } \\
\left(\mathbf{L ~ s} \mathbf{~}^{\mathbf{1}}\right)\end{array}$ & $\begin{array}{c}\text { MPS } \\
\left(\mathbf{m g ~ L}^{\mathbf{- 1}}\right)\end{array}$ \\
\hline $\mathrm{A}_{1.1}$ & 11,0 & 8,00 & $\mathrm{~A}_{2.1}$ & 6,3 & 23,86 \\
$\mathrm{~A}_{1.2}$ & 14,3 & 10,33 & $\mathrm{~A}_{2.2}$ & 11,2 & 48,21 \\
$\mathrm{~A}_{1.3}$ & 31,8 & 17,67 & $\mathrm{~A}_{2.3}$ & 17,9 & 57,41 \\
$\mathrm{~A}_{1.4}$ & 53,0 & 21,33 & $\mathrm{~A}_{2.4}$ & 53,0 & 80,64 \\
$\mathrm{~A}_{1.5}$ & 62,0 & 50,19 & $\mathrm{~A}_{2.5}$ & 35,5 & 39,04 \\
$\mathrm{~A}_{1.6}$ & 50,0 & 50,00 & $\mathrm{~A}_{2.6}$ & 23,5 & 26,11 \\
$\mathrm{~A}_{1.7}$ & 33,6 & 36,14 & $\mathrm{~A}_{2.7}$ & 15,5 & 17,34 \\
$\mathrm{~A}_{1.8}$ & 19,2 & 19,17 & $\mathrm{~A}_{2.8}$ & 10,0 & 12,94 \\
$\mathrm{~A}_{1.9}$ & 15,5 & 12,64 & $\mathrm{~A}_{2.9}$ & 8,0 & 11,57 \\
& $\mathrm{CMNQ}$ & & $C M N Q_{\mathrm{MPS}}$ & 46,89 \\
\hline
\end{tabular}

$\mathrm{A}_{1.1}$ a $\mathrm{A}_{1.9}$ representam o período de amostragem antes do corte

$\mathrm{A}_{2.1}$ a $\mathrm{A}_{2.9}$ representam o período de amostragem depois do corte

De maneira geral foi possível observar que as concentrações de MPS mostraram relações positivas com as vazões instantâneas, evidenciando suas maiores concentrações nas maiores vazões e menores concentrações juntamente com as mais baixas vazões. Contudo, essa maior carga particulada transportada fluvialmente se mostrou mais pronunciada no segundo período de amostragem (após o corte da madeira) do que em relação ao primeiro, especialmente durante as subidas das águas e nos picos de cheia, com valores de 57,4 e $80,6 \mathrm{mg} \mathrm{L}^{-1}$, para respectivas vazões instantâneas de 17,9 e $53,0 \mathrm{~L} \mathrm{~s}^{-1}$ (coletas $\mathrm{A}_{2.3}$ e $\mathrm{A}_{2.4}$, da segunda amostragem), contra 21,33 e 50,19 mg L $\mathrm{mg}^{-1}$, para vazões de 53,0 e 62,0 L s${ }^{-1}$ (coletas $\mathrm{A}_{1.3}$ e $\mathrm{A}_{1.4}$ da primeira amostragem). Tais aportes de material particulado no segundo período de amostragem podem ter ocorrido em função da mudança do uso do solo, decorrente do corte da madeira em 10,2\% da área da microbacia de drenagem, o que deixou o solo sem cobertura florestal mais densa, e também devido à significativa declividade do terreno dessa área de colheita (em torno de 38\%), o que possivelmente contribuiu para um maior escoamento superficial desse material para dentro do canal fluvial. Esse mesmo preceito de maior aporte de MPS na amostragem após colheita de madeira também foi evidenciada em termos de concentrações médias normalizadas pelas vazões, que se mostrou maior cerca de 1,5 vezes em relação ao primeiro período, com valores respectivos de $46,89 \mathrm{mg} \mathrm{L}^{-1}$ e $32,08 \mathrm{mg} \mathrm{L}^{-1}$. Vital et al. (1999) e Câmara e Lima (1999), observaram o mesmo comportamento após corte raso da plantação de eucaliptos em microbacias localizadas respectivamente nos municípios de Santa Branca e Itatinga, ambas no Estado de São Paulo, indicando maior suscetibilidade à erosão nas microbacias, após a colheita da madeira. 


\subsection{Relação concentração-vazão de MPS}

Os aspectos dinâmicos da carga particulada das águas fluviais do córrego Entre Rios também foram avaliados no presente estudo pelas relações entre as concentrações de MPS e as respectivas vazões instantâneas durante as duas amostragens, conforme ilustra a Figura 7.
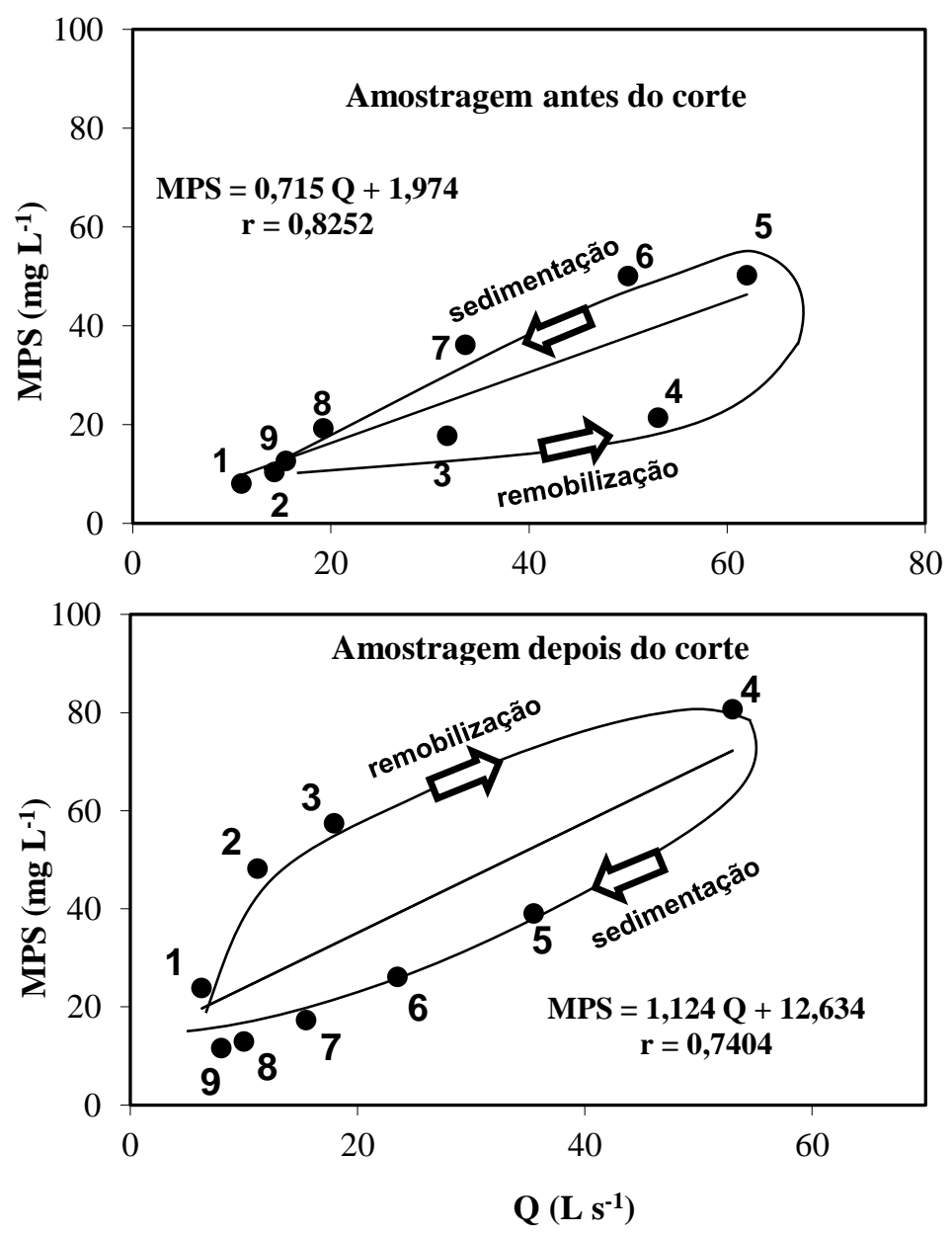

Figura 7. Relações entre as concentrações de MPS $\left(\mathrm{mg} \mathrm{L}^{-1}\right)$ e vazões instantâneas ( $\mathrm{Q}$ em L s $\left.{ }^{-1}\right)$, evidenciando os processos de remobilização e sedimentação (curvas de histerese) para as duas amostragens antes e depois do corte da madeira, nas águas fluviais do córrego Entre Rios, em Angatuba - São Paulo.

O modelo que melhor se ajustou ao comportamento das concentrações de MPS em função das vazões foi o linear, característicos para médios e pequenos rios (Probst e Bazerbachi, 1986), sendo possível evidenciar significativos coeficientes de correlação para ambas as amostragens ( $\mathrm{p}>0,01$ ). Pode ser ainda observado, pelo coeficiente angular da equação de regressão, uma maior taxa de transporte de MPS durante a amostragem realizada depois do corte da madeira, o qual foi de $1,124 \mathrm{mg} \mathrm{s}^{-1}$, em comparação com a primeira amostragem antes do corte que apresentou $0,715 \mathrm{mg} \mathrm{s}^{-1}$, confirmando o alto poder de arraste desse material para as águas fluviais pós supressão da floresta.

A avaliação dos aspectos dinâmicos da carga particulada envolveu ainda a observação das ocorrências dos processos de remobilização e sedimentação do MPS nas águas fluviais do córrego Entre Rios em ambas as amostragens (Figura 7). De acordo com Carmouze (1974), Probst e Bazerbachi (1986), Kattan e Probst (1987) e Kattan et al. (1987), os processos de remobilização e de deposição de material em suspensão seguem basicamente 3 fases distintas: 
(a) a primeira caracterizada por um significativo aumento das concentrações de sedimentos com a vazão, associados aos processos erosivos mecânicos e transportados para o rio preferencialmente por escoamentos superficiais. Este período corresponde também à remobilização dos sedimentos que estão acumulados no leito do canal fluvial e que são intensificadas pela contribuição das componentes subsuperficial e subterrânea; (b) a segunda caracterizada pela diminuição das concentrações dos sedimentos no momento em que as vazões começam a diminuir com o fim dos eventos chuvosos; (c) e a terceira fase caracterizada pela diminuição da concentração dos sedimentos, juntamente com a vazão. Esta fase corresponde à deposição dos sedimentos no leito dos sistemas fluviais.

Pelos resultados obtidos foi possível verificar que durante o processo de remobilização da amostragem posterior ao corte de madeira (pontos de 1 a 4), as concentrações de MPS se mostraram superiores em relação ao processo de sedimentação (pontos de 4 a 9), com uma variação no sentido horário, característicos desses ambientes fluviais, com subida e descida de água no canal bastante rápida, conforme evidenciado em bacias de drenagem de diferentes magnitudes (Meade et al., 1985; Probst et al., 1992; Mortatti, 1995; Ferraz e Mortatti, 2002; Fernandes et al., 2012).

Por outro lado, durante o período de amostragem anterior a realização do corte esse processo se inverte, sendo evidenciados maiores concentrações de MPS durante o processo de sedimentação e variando no sentido anti-horário. Tal situação, pouco vista na literatura, pode ter sido influenciada pelo período bastante úmido (chuvas intensas), apresentando uma subida rápida das águas, mas com um lento processo de recesso, sendo que essa dinâmica pode estar associada às significativas contribuições dos fluxos subterrâneos.

\subsection{Quantificação da carga particulada fluvial}

A quantificação da carga total e específica de MPS, calculada pelo método de fluxo instantâneo, para os dois períodos estudados pode ser observado na Tabela 6. Para melhor interpretação da dinâmica de MPS nas águas fluviais do córrego Entre Rios, exercidas pelas flutuações das vazões, os resultados dos fluxos instantâneos foram dispostos na forma de distribuições temporais, como mostra a Figura 8.

Pelos resultados obtidos foi possível observar que os fluxos instantâneos relativos ao período de amostragem antes do corte da madeira se mostraram mais bem distribuídos ao longo do respectivo hidrograma gerado, inclusive apresentando mais fluxos representativos nos períodos de subida das águas e no de recesso. Ao passo que no período de amostragem depois do corte, um fluxo bastante significado de cerca de $15.385,9 \mathrm{~g} \mathrm{~h}^{-1}$ pode ser verificado no pico de cheia, diferenciando-o dos demais fluxos que se mostraram preferencialmente distribuídos entre os períodos de subida e de descida das águas. Essa dinâmica ocorrida na segunda amostragem confirmou o rápido e pronunciado processo de arraste desse material particulado para o canal fluvial, o qual corroborou com o tempo de residência da chuva na microbacia (aproximadamente de 2 horas) e mostrou de forma ainda mais detalhada a influência antrópica promovida especialmente pelo corte da madeira no processo erosivo mecânico dessa microbacia de drenagem.

Mesmo com essas diferenças evidenciadas nos comportamentos e distribuições dos fluxos nos dois hidrogramas gerados nos períodos estudados foi possível verificar resultados similaridades em termos de fluxos totais de MPS que apresentaram valores de $3.728,3 \mathrm{~g} \mathrm{~h}^{-1}$, antes do corte, e de $3.393,8 \mathrm{~g} \mathrm{~h}^{-1}$ depois do corte, o que representou em termos de fluxos específicos $2.330,1 \mathrm{~g} \mathrm{~km}^{-2} \mathrm{~h}^{-1} \mathrm{e} 2.121,1 \mathrm{~g} \mathrm{~km}^{-2} \mathrm{~h}^{-1}$, respectivamente.

Os valores mais elevados obtidos na primeira amostragem podem ser justificados ao período de intensas chuvas ocorridas anteriormente a realização dessa amostragem. Esse fato aliado à maior precipitação ocorrida no dia da coleta proporcionaram maiores volumes de água no sistema fluvial devido às contribuições superficiais e fluxos subterrâneos, gerando 
maiores vazões nesse período e ocasionando maior lentidão do processo de sedimentação da carga sólida, conforme evidenciado anteriormente e constatado pela análise da Figura 8. Como a quantificação do fluxo de MPS baseou-se no quociente entre valores de concentrações e vazões, tal fato pode ter contribuído para obtenção de maiores fluxos de sedimentos nessa referida amostragem realizada antes do corte da madeira.

Tabela 6. Resultados dos fluxos instantâneos obtidos entre as concentrações de material particulado em suspensão e vazões (MPS em $\mathrm{g} \mathrm{h}^{-1}$ ), incluindo os fluxos totais $\left(\Sigma \mathrm{F}_{\mathrm{TAC}(\mathrm{MPS})}\right.$ e $\left.\Sigma \mathrm{F}_{\mathrm{TDC}(\mathrm{MPS})} \mathrm{em}_{\mathrm{g} \mathrm{h}}{ }^{-1}\right)$ e específicos $\left(\Sigma \mathrm{F}_{\mathrm{EAC}(\mathrm{MPS})} \mathrm{e}\right.$ $\Sigma \mathrm{F}_{\mathrm{EDC}(\mathrm{MPS})} \mathrm{em} \mathrm{g} \mathrm{km}^{-2} \mathrm{~h}^{-1}$ ) nos períodos antes de depois do corte da madeira, para as amostras de águas fluviais do córrego Entre Rios.

\begin{tabular}{cccc}
\hline \multicolumn{2}{c}{ Amostragem antes do corte } & \multicolumn{2}{c}{ Amostragem depois do corte } \\
Mmostras & $\begin{array}{c}\text { MPS } \\
\left(\mathrm{g} \mathrm{h}^{-1}\right)\end{array}$ & Amostras & $\left(\mathrm{g} \mathrm{h}^{-1}\right)$ \\
\hline $\mathrm{A}_{1.1}$ & 316,8 & $\mathrm{~A}_{2.1}$ & 539,4 \\
$\mathrm{~A}_{1.2}$ & 533,3 & $\mathrm{~A}_{2.2}$ & 1945,2 \\
$\mathrm{~A}_{1.3}$ & 2021,4 & $\mathrm{~A}_{2.3}$ & 3706,8 \\
$\mathrm{~A}_{1.4}$ & 4072,9 & $\mathrm{~A}_{2.4}$ & 15385,9 \\
$\mathrm{~A}_{1.5}$ & 11202,3 & $\mathrm{~A}_{2.5}$ & 4991,6 \\
$\mathrm{~A}_{1.6}$ & 9000,0 & $\mathrm{~A}_{2.6}$ & 2209,7 \\
$\mathrm{~A}_{1.7}$ & 4374,2 & $\mathrm{~A}_{2.7}$ & 966,2 \\
$\mathrm{~A}_{1.8}$ & 1328,3 & $\mathrm{~A}_{2.8}$ & 466,0 \\
$\mathrm{~A}_{1.9}$ & 704,4 & $\mathrm{~A}_{2.9}$ & 333,1 \\
\hline$\sum \mathrm{F}_{\mathrm{TAC}(\mathrm{MPS})}\left(\mathrm{g} \mathrm{h}^{-1}\right)$ & 33553,5 & $\sum \mathrm{F}_{\mathrm{TDC}(\mathrm{MPS})}\left(\mathrm{g} \mathrm{h}^{-1}\right)$ & 30544,0 \\
$\sum \mathrm{F}_{\mathrm{EAC}(\mathrm{MPS})}$ & & $\sum \mathrm{F}_{\mathrm{EDC}(\mathrm{MPS})}$ & \\
$\left(\mathrm{g} \mathrm{km}^{-2} \mathrm{~h}^{-1}\right)$ & 20970,9 & $\left(\mathrm{~g} \mathrm{~km}^{-2} \mathrm{~h}^{-1}\right)$ & 19090,0 \\
\hline
\end{tabular}

Comparativamente esses fluxos específicos de MPS obtidos no presente estudo em ambos os períodos de amostragem se mostraram superiores aos observados por Câmara e Lima (1999) e Vital et al. (1999), que apresentaram no primeiro ano após corte raso da madeira perdas de sedimentos da ordem de 692 e $473 \mathrm{~g} \mathrm{~km}^{-2} \mathrm{~h}^{-1}$, respectivamente, para as microbacias do Tinga e de Santa Branca (São Paulo). No entanto, os fluxos de MPS observados para microbacia do córrego Entre Rios se mostraram muito inferiores ao obtido por Bibian (2007) para a microbacia do córrego Barra Bonita (São Paulo), que apresentou para um evento chuvoso de $60 \mathrm{~mm}$ cerca de $14.835 \mathrm{~g} \mathrm{~km}^{-2} \mathrm{~h}^{-1}$, sendo que essa diferença pode estar relacionada a diversos fatores como, por exemplo, área da microbacia de drenagem (maior cerca de 18 vezes), volume do evento chuvoso (cerca de 2 vezes maior) e condições de saturação dos solos.

Entretanto, fica evidente a vulnerabilidade desses ecossistemas localizados especialmente em microbacias de drenagem, principalmente em relação às diversas intervenções antrópicas nas mesmas. Tal fato justifica a importância e relevância de estudos verificando a influência de diferentes classes de precipitações que podem, como evidenciado no presente estudo, influenciar diretamente a qualidade das águas superficiais e promover alterações significativas 
nos comportamentos dinâmicos das cargas fluviais.

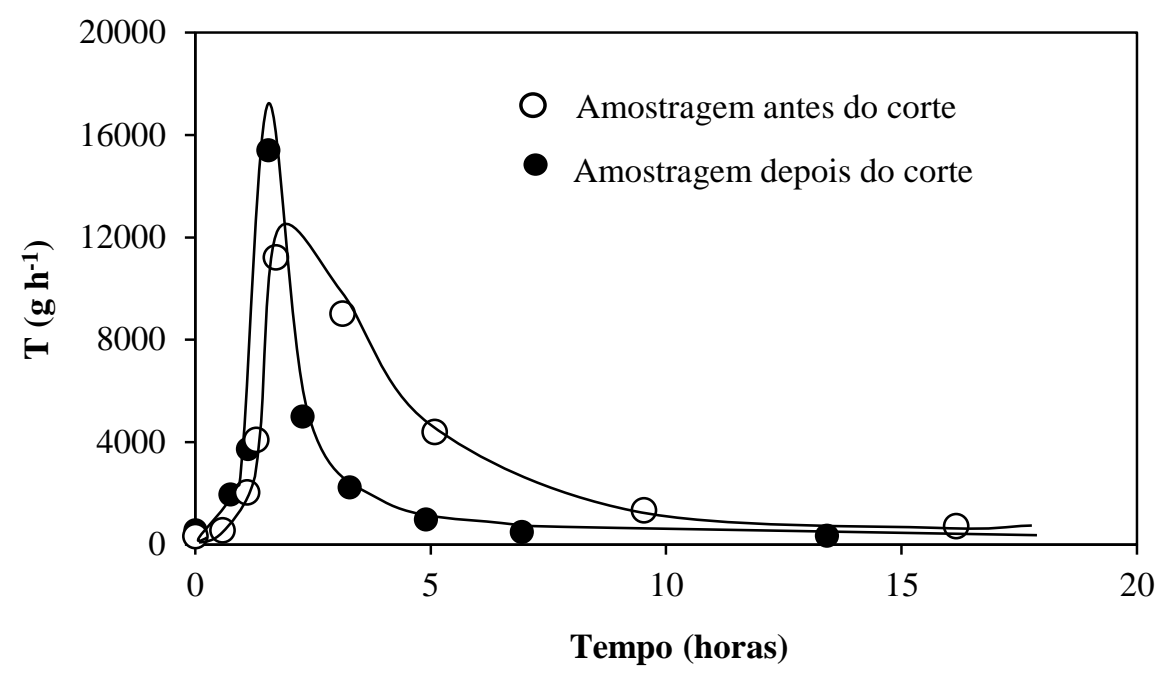

Figura 8. Variabilidade temporal dos fluxos instantâneos $\left(\mathrm{g} \mathrm{h}^{-1}\right)$ obtidos entre os valores de MPS e das vazões para os períodos estudados antes e depois do corte da madeira nas águas fluviais do córrego Entre Rios, em Angatuba (SP).

\section{CONCLUSÕES}

Os dados obtidos pelos resultados analíticos das principais espécies químicas inorgânicas dissolvidas e do material particulado em suspensão, juntamente com a aplicação de modelos hidrogeoquímicos, permitiu de modo satisfatório avaliar o comportamento dinâmico das cargas dissolvida e particulada nas águas fluviais da microbacia do córrego Entre Rios durante a ocorrência de dois eventos chuvosos.

As concentrações das principais espécies químicas inorgânicas dissolvidas estudadas se mostraram fortemente influenciadas pelas contribuições atmosféricas e processos hidrológicos envolvidos nos períodos estudados. Basicamente, o comportamento dinâmico da maioria das espécies químicas nas águas fluviais seguiu dois padrões inerentes: 1) a ocorrência de um aporte significativo das concentrações dessas espécies, especialmente no processo de subida das águas, associado ao rápido processo de escoamento superficial, sendo tal processo ocorrido anteriormente aos picos das vazões e 2) e posteriormente a ocorrência dos padrões de diluições característicos, ocorridos concomitantemente com os mais altos valores de vazões e já com as expressivas contribuições provenientes dos escoamentos subterrâneos.

As comparações entre as curvas de distribuição das espécies químicas dissolvidas com as curvas de diluição teórica permitiram evidenciar de forma mais detalhada esse processo de diluição. Além disso, segundo a aplicação deste modelo foi possível ainda verificar que as espécies químicas inorgânicas dissolvidas $\mathrm{SiO}_{2}, \mathrm{HCO}_{3}^{-}, \mathrm{Ca}^{2+}, \mathrm{Na}^{+}, \mathrm{Mg}^{2+} \mathrm{e} \mathrm{NO}_{3}^{-}$apresentaram aportes de origem difusa, ou seja, com ocorrências bastante significativas ao longo de toda microbacia de drenagem, associadas principalmente à alteração de rochas e possivelmente dos aportes provenientes dos eventos chuvosos, mas também, como nos casos de $\mathrm{K}^{+}, \mathrm{Cl}^{-}$e $\mathrm{SO}_{4}{ }^{2-}$, e especialmente após o corte da madeira, dos aportes de origem antrópica, associados aos tratos culturais ocorridos ao longo da microbacia de drenagem.

O comportamento dinâmico de MPS se mostrou contrário ao da carga dissolvida, apresentando concentrações mais elevadas nas mais altas vazões. Apesar da utilização do modelo linear para explicar as distribuições das concentrações de MPS em função das vazões 
foi possível observar em ambas às amostragens a ocorrência dos processos remobilização e de deposição do material particulado nas águas fluviais do córrego Entre Rios, se mostrando bastantes semelhantes ao evidenciado em grandes e médias bacias de drenagem. Foi possível observar, no entanto, que o processo de remobilização da amostragem posterior ao corte de madeira se mostrou superior ao processo de sedimentação e com variação no sentido horário, diferentemente do período anterior ao corte da madeira, em que o processo de sedimentação se mostrou mais significativo, evidenciando a importância das contribuições dos subterrâneos nesse sistema hídrico durante o período de chuvas intensas.

Comparado a outros métodos, o emprego do método de fluxo instantâneo se mostrou mais apropriado para estimativas das cargas dissolvida e particulada transportadas fluvialmente dos dois eventos chuvoso ocorridos na microbacia devido à obtenção dos fluxos em todas as fases dos hidrogramas, não dependendo de médias de concentrações e vazões, diminuindo a possibilidade de gerar valores subestimados ou superestimados.

\section{AGRADECIMENTOS}

Os autores agradecem ao Conselho Nacional de Desenvolvimento Científico e Tecnológico, CNPq (Processo n ${ }^{\circ}$ 135148/2007-3) e à Fundação de Amparo à Pesquisa do Estado de São Paulo -FAPESP (Processo $n^{\circ}$ 2006/51301-7) pelo suporte financeiro para desenvolvimento da pesquisa.

\section{REFERÊNCIAS}

AHEARN, D. S.; SHEIBLEY, R. W.; DAHLGREN, R. A.; KELLER, K. E. Temporal dynamics of stream water chemistry in the last free-flowing river draining the western Sierra Nevada, California. Journal of Hydrology, v. 295, p. 47-63, 2004. http;//dx.doi.org/10.1016/j.jhydrol.2004.02.016

BEIGHLEY, R. E.; MOGLEN, G. E. Adjusting measured peak discharges from an urbanizing watershed to reflect a stationary land use signal. Water Resources Research, v. 39, n. 4, p. 4.1-4.11, 2003. http://dx.doi.org/10.1029/2002WR001846

BETSON, R. P.; MARIUS, J. B. Source areas of storm runoff. Water Resources Research, v. 5, p. 574-582, 1969. http://dx.doi.org/10.1029/WR005i003p00574

BIBIAN, J. P. R. Caracterização hidrogeoquímica da microbacia de drenagem do córrego Barra Bonita. 2007. 194 p. Dissertação (Mestrado) - Centro de Energia Nuclear na Agricultura, Universidade de São Paulo, Piracicaba, 2007.

BONELL, M. Hydrological processes and implications for land management in forests and agricultural areas of the wet tropical coast of north-east Queensland. In: WARNER, R. F. (Ed.). Fluvial geomorphology of Australia. New York: Academic Press, 1988. p. 41-68.

BONELL, M. The applications of hillslope hydrology in forest land-management issues: the tropical north-east Australian experience. In: BRAGA, B. P. F.; FERNANDEZJAUREGUI, C. A. (Ed.). Water management of the Amazon basin. Montevideo: UNESCO, 1991. p. 4582.

BORMANN, F. H.; LIKENS, G. E.; FISCHER, D. W.; PIERCE, R. S. Nutrient loss accelerated by clearcutting of a forest ecosystem. Science, v. 159, n. 3817, p. 882-4, 1968. http//dx.doi.org/10.1126/science.159.3817.882 
BORTOLETTO JR., M. J. Características hidrogeoquímicas e processos erosivos mecânicos e químicos nas bacias de drenagem dos rios Tietê e Piracicaba. 2004. 202 p. Tese (Doutorado em Ciências) - Centro de Energia Nuclear na Agricultura, Universidade de São Paulo, Piracicaba, 2004.

BOS, M. G. Discharge measurement structures. Wageningen: ILRI, 1976. 464p.

CÂMARA, C. D.; LIMA, W. P. Corte raso de uma plantação de Eucalyptus saligna de 50 anos: impactos sobre o balanço hídrico e a qualidade da água em uma microbacia experimental. Scientia Forestalis, v. 56, p. 41-58, 1999.

CÂMARA, C. D.; LIMA, W. P.; VIEIRA, S. A. Corte raso de uma plantação de Eucalyptus saligna de 50 anos: impactos sobre a ciclagem de nutrientes em uma microbacia experimental. Scientia Forestalis, v. 57, p. 99-109, 2000.

CARMOUZE, J. P. La regulation hydrogéochimique du lac Tchad. Contribution à l'analyse biodynamique du système endoréique en milieu continental. Trav. Doc. Orstom, v. 58, p. 418, 1974.

CARVALHO, K. H. A.; SILVA, M. L.; SOARES, N. S. Efeito da área e da produtividade na produção de celulose no Brasil. Revista Árvore, v. 36, n. 6, p. 1119-1128, 2012. http://dx.doi.org/10.1590/S0100-67622012000600012

CRUCIANI, D. E. Hidráulica, equações, tabelas, gráficos. São Pauo: Universidade de São Paulo, 1993. 129p.

DE MORAES, J. M.; SCHULER, A. E.; DUNNE. T.; FIGUEIREDO, R. O.; VICTORIA, R. L. Water storage and runoff processes in plinthic soils under forest and pasture in Eastern Amazonia. Hydrological Processes, v. 20, n. 12, p. 2509-2526, 2006. http://dx.doi.org/10.1002/hyp.6213

DUNNE. T.; BLACK, R. D. Partial-area contributions to storm runoff in a small New England watershed. Water Resources Research, v. 6, p. 1297-1311, 1970. http://dx.doi.org/10.1029/WR006i005p01296

DUNNE, T. Field studies of hillslope processes. In: KIRKBY, M. J. (Ed.). Hillslope hydrology. Wiley: Chichester, 1978. p. 227-293.

DUNNE, T. Relation to field studies and modeling in the prediction of storm runoff. Journal of Hydrology, v. 65, p. 25-48, 1983. http://dx.doi.org/ 10.1016/0022-1694(83)90209-3

EDMOND, J. M. High precision determination of titration alkalinity and total carbon dioxide content of seawater by potentiometric titration. Deep-Sea Research. Part I: Oceanographic Research Papers, v. 17, n. 4, p. 737-750, 1970. http://dx.doi.org/10.1016/0011-7471(70)90038-0

EMPRESA BRASILEIRA DE PESQUISA AGROPECUÁRIA - EMBRAPA. Sistema brasileiro de classificação de solos. $2^{\text {a }}$ ed. Brasília, 2006. 306p.

FELLER, M. C.; KIMMINS, J. P. Effects of clearcutting and slash burning on stream water chemistry and watershed nutrient budgets in southwestern British Columbia. Water resources research, v.20, n.1, p.29-40, 1984. http://dx.doi.org/10.1029/ WR020i001p00029 
FERNANDES, A. M.; NOLASCO, M. B.; HISSLER, C.; MORTATTI, J. Mechanical erosion in a tropical river basin in southeastern Brazil: chemical characteristics and annual fluvial transport mechanisms. Journal of Geological Research, v. ID 127109, p. 8, 2012. http://dx.doi.org/10.1155/2012/127109

FERNANDES, A. M. Características hidrogeoquímicas da bacia de drenagem do rio Sorocaba, SP: processos erosivos mecânicos e químicos. 2012. 241 f. Tese (Doutorado) - Centro de Energia Nuclear na Agricultura, Universidade de São Paulo, Piracicaba, 2012.

FERRAZ, F. F. B.; MORTATTI, J. Avaliação do processo erosivo mecânico em bacia subtropical desenvolvida pela análise de sedimentos finos em suspensão. Geociências, v. 21, n. 1/2, p. 113-120, 2002.

GUIMARÃES, R. Z.; OLIVEIRA, F. A.; GONÇALVES, M. Avaliação dos impactos da silvicultura sobre a qualidade dos recursos hídricos superficiais. Scientia Forestalis, v. 38 , n. 87 , p. 377-390, 2010.

HALL, F. R. Dissolved solids-discharge relationships. 2. Applications to field data. Water Resources Research, v. 7, n. 3, p. 591-601, 1971. http://dx.doi.org/10.1029/ WR007i003p00591

HARRIMAN, R.; GILLESPIE, E.: KING, D.; WATT, A. W.; CHRISTIE, A. E. G.; COWAN, A. A. et al. Short-term ionic responses as indicators of hydrochemical processes in the Allt-a-Mharcaidh Catchment, Western Cairngorms, Scotland. Journal of Hydrology, v. 116, n. 1-4, p. 267-285, 1990. hhtp://dx.doi.org/10.1016/00221694(90)90127-J

HINO, M.; HASEBE, M. Identification and prediction of nonlinear hydrologic systems by the filter-separation Autoregressive (AR) method: extension to hourly hydrologic data. Journal of Hydrologic, v. 68, p. 181-210, 1984. hhtp://dx.doi.org/10.1016/00221694(84)90211-7

HOPMANS, P.; FLINN, D. W.; FFARREL, P. W. Nutrient dynamics of forested catchments in southeastern Australia and changes in water quality and nutrient exports following clearing. Forest ecology and Management, v. 20, n. 34, p. 209-231, 1987. http://dx.doi.org/10.1016/0378-1127(87)90081-8

HORNBECK, J. W.; PIERCE, R. S.; LIKENS, G. E. Moderating the impact of contemporary forest cutting on hydrological and nutrients cycles. New Hampshire IAHSPublication, v. 117, p. 423-429, 1975.

INSTITUTO DE PESQUISAS TECNOLÓGICAS DO ESTADO DE SÃO PAULO. Mapa geológico do estado de São Paulo. São Paulo, 1981. p. 126

KATTAN, Z.; PROBST, J. L. Transport en suspension et en solution par la Moselle em période de crue. Actes Des Journées D'hydrologie, "Crues et inondations", Strasbourg, p. 143-167, 1987.

KATTAN, Z.; GAC, J. I.; PROBST, J. L. Suspended sediment load and mechanical erosion in the Senegal basin, estimation of the surface runoff concentration and relative contributions of channel and slope erosion. Journal of Hydrology, v. 92, p. 59-76, 1987. http://dx.doi.org/10.1016/0022-1694(87)90089-8 
KATTAN, Z. Géochimie et hydrologie dês eaix fluviales dês bassins de la moselle et de la Mossig. Transports dissous et particularies. Cycles biogeochimiques dês éléments. 1989. 220 f. These (Doctor) - Centre de Géochimie de la Surfaze, Université Louis Pasteur, Strasbourg, 1989.

KÖPPEN, W. P. Climatologia: com um estúdio de lós climas de La tierra. 1. ed. México: Fondo de Cultura Economica, 1948. 478 p.

LIMA, W. P. O. Papel hidrológico da floresta na proteção dos recursos hídricos. Revista Silvicultura, v. 41, p. 59-62, 1986.

MEADE, R. H. Suspended sediment in the Amazon river and its tributaries in Brazil during 1982-84. U.S. Geological Survey, Open-File Report, 85-492, 1985.

MEYBECK, M. Composition chimique des ruisseauxnon pollutes de France. Science Geology Bulletin, v. 39, n. 1, p. 3-77, 1986.

MORTATTI, J. Erosão na Amazônia: processos, modelos e balanço. 1995. 155p. Tese (Livre-docência) - Escola Superior de Agricultura "Luiz de Queiroz", Universidade de São Paulo, Piracicaba, 1995.

MORTATTI, J.; BORTOLETTO, J. R.; PROBST, J. L. Piracicaba river basin: mechanical and chemical erosions. Geociências, v. 22, n. 1, p. 177-196, 2003.

MORTATTI, J.; PROBST, J. L.; FERNANDES, A. M.; MORTATTI, B. C.; OLIVEIRA, H. Influence of discharge on silicate weathering dynamics of the Tiete river basin: major cations and dissolved silica approach. Geochimica Brasiliensis, v. 22, n. 1, p. 15-26, 2008 .

MOUKOLO, N.; LARAQUE, A.; OLIVRY, J.C.; BRICQUET, J. P. Transport en solution et en suspension par le fleuve Congo (Zaire) et ses principaux affluents de rive droite. $\begin{array}{lllllll}\text { Hidrological Science Journal, } & \text { v. 38, p. }\end{array}$ http://dx.di.org/10.1080/02626669309492651

OLIVEIRA, H.; VENDRAMINI, D.; MORTATTI, J. Transporte de espécies químicas dissolvidas em águas fluviais de uma microbacia com eucaliptos em Angatuba, São Paulo. Revista Geociências, v. 28, n. 1, p. 79-89, 2009.

PROBST, J. L.; NKOUNKOU, R. R.; KREMPP, G.; BRICQUET, J. P.; THIÉBAUX, J. P.; OLIVRY, J. C. Dissolved major elements exported by the Congo and the Ubangi rivers during the period 1987-1989. Journal of Hydrology, v. 135, p. 237-257, 1992. http://dx.doi.org/10.1016/0022-1694(92)90090-I

PROBST, J. L.; BAZERBACHI, A. Transports en solution et en suspension par la Garonne supérieure. Science Géologiques Bulletin, v. 1, p. 79-98, 1986.

PROBST, J. L. Géochimie et hydrologie de l'érosion continentale: méchanisms, bilan global actuel et flutuations au cours des 500 derniers millions d'années. Sciences Géologiques Bulletin, v. 94, p. 1-161, 1992.

RANZINI, M.; LIMA, W. P. Comportamento hidrológico, balanço de nutrientes e perdas de solo em duas microbacias reflorestadas com Eucalyptus, no Vale do Paraíba, SP. Scientia Forestalis, v. 61, p. 144-159, 2002. 
SIDLE, R. C.; TSUBOYAMA, Y.; NOGUCHI, S.; HOSODA, I.; FUJIEDA, M.; SHIMIZU, T. Seasonal hydrologic response at various spatial scales in a small forested catchment, Hitachi Ohta, Japan. Journal of Hydrology, v. 168, p. 227-250, 1995.

STEVENS, P. A.; NORRIS, A. D.; WILLIANS, T. G. Nutrient losses after clearfelling in Bedgelert Forest: a comparison of the effects of conventional and whole-tree harvest on soil water chemistry. Forestry, v. 68, n. 2, p. 115-131, 1995. http://dx.doi.org/10.1093/forestry/68.2.115

VENDRAMINI, D. Aspectos hidrogeoquímicos de uma microbacia reflorestada com Eucalyptus grandis no município de Angatuba - São Paulo. 2009. 195 f. Dissertação (Mestrado) - Centro de Energia Nuclear na Agricultura, Universidade de São Paulo, Piracicaba, 2009.

VENDRAMINI, D. Monitoramento hidrogeoquímicos do rio Piracicaba: aspectos dinâmicos do transporte de material dissolvido e particulado. 2013. $232 \mathrm{f}$. Tese (Doutorado) - Centro de Energia Nuclear na Agricultura, Universidade de São Paulo, Piracicaba, 2013.

VENDRAMINI, D.; BONASSI, J. A.; MORTATTI, J. Aspectos da influência antrópica na carga dissolvida do rio Piracicaba (SP). Revista Geologia da USP, Série Científica, v. 13, n. 13, p. 99-112, 2013.

VITAL, A. R. T.; LIMA, W. P.; CAMARGO, F. R. A. Efeitos do corte raso de plantação de Eucalyptus sobre o balanço hídrico, a qualidade da água e as perdas de solo e de nutrientes em uma microbacia no Vale do Paraíba, SP. Scientia Forestalis, n. 55, p. 516, 1999. 